\title{
POSTNATAL CHANGES TO THE MECHANICAL PROPERTIES OF ARTICULAR CARTILAGE ARE DRIVEN BY THE EVOLUTION OF ITS COLLAGEN NETWORK
}

\author{
A.R. Gannon ${ }^{1,2}$, T. Nagel ${ }^{3}$, A.P. Bell ${ }^{4}$, N.C. Avery ${ }^{5}$ and D.J. Kelly ${ }^{1,2,6, *}$
}

${ }^{1}$ Trinity Centre for Bioengineering, Trinity Biomedical Sciences Institute, Trinity College Dublin, Dublin, Ireland. ${ }^{2}$ Department of Mechanical and Manufacturing Engineering, School of Engineering, Trinity College Dublin, Dublin, Ireland.

${ }^{3}$ Department of Environmental Informatics, Helmholtz Centre for Environmental Research GmbH - UFZ, Leipzig, Germany.

${ }^{4}$ CRANN Advanced Microscopy Laboratory, Trinity College Dublin, Dublin, Ireland.

${ }^{5}$ Collagen Research Group, Division of Molecular and Cellular Biology, University of Bristol, Bristol, UK.

${ }^{6}$ Advanced Materials and Bioengineering Research Centre (AMBER),

Royal College of Surgeons in Ireland and Trinity College Dublin, Dublin, Ireland.

\section{Abstract}

While it is well established that the composition and organisation of articular cartilage dramatically change during skeletal maturation, relatively little is known about how this impacts the mechanical properties of the tissue. In this study, digital image correlation was first used to quantify spatial deformation within mechanically compressed skeletally immature (4 and 8 week old) and mature ( 1 and 3 year old) porcine articular cartilage. The compressive modulus of the immature tissue was relatively homogeneous, while the stiffness of mature articular cartilage dramatically increased with depth from the articular surface. Other, well documented, biomechanical characteristics of the tissue also emerged with skeletal maturity, such as strain-softening and a depth-dependent Poisson's ratio. The most significant changes that occurred with age were in the deep zone of the tissue, where an order of magnitude increase in compressive modulus (from 0.97 MPa to 9.4 MPa for low applied strains) was observed from 4 weeks postnatal to skeletal maturity. These temporal increases in compressive stiffness occurred despite a decrease in tissue sulphated glycosaminoglycan content, but were accompanied by increases in tissue collagen content. Furthermore, helium ion microscopy revealed dramatic changes in collagen fibril alignment through the depth of the tissue with skeletal maturity, as well as a fivefold increase in fibril diameter with age. Finally, computational modelling was used to demonstrate how both collagen network reorganisation and collagen stiffening play a key role in determining the final compressive mechanical properties of the tissue. Together these findings provide a unique insight into evolving structure-function relations in articular cartilage.

Keywords: Articular cartilage, collagen, Young's modulus, digital image correlation, helium ion microscopy, maturation, structure-function relations.

*Address for correspondence:

Dr. Daniel Kelly

Trinity Centre for Bioengineering

Department of Mechanical Engineering

Parsons Building, Trinity College Dublin

Dublin 2, Ireland

Telephone Number: +353-1-896-3947

FAX Number: +353-1-679-5554

E-mail: kellyd9@tcd.ie
Articular cartilage consists of an extracellular matrix made up of water ( $80 \%$ wet weight $)$, proteoglycans $(\sim 25$ $35 \%$ dry weight) and collagen ( 50-60\% dry weight), together with a small concentration of non-collagenous matrix proteins and glycoproteins $(\sim 15-20 \%$ dry weight $)$ (Brama et al., 2000; Buckwalter et al., 2005). The tissue is synthesised and remodelled by chondrocytes, which vary in organisation and phenotype with depth from the articular surface (Stockwell, 1970). During postnatal development and skeletal maturation, the biochemical composition of articular cartilage changes both spatially and temporally. Collagen concentration and pyridinoline cross-link concentration has been reported to increase with maturation, whilst the glycosaminoglycan concentration and percentage water content remain unchanged or decrease slightly (Williamson et al., 2003; Temple et al., 2007; Julkunen et al., 2009). The specific types of glycosaminoglycans (GAGs) within the tissue also change; chondroitin-4 sulphate is reported to be the predominant GAG in immature cartilage, while chondroitin-6 sulphate is predominant in mature tissue (Torzilli et al., 1998). Structurally, significant alterations of the collagen network also take place during postnatal development (Buckwalter et al., 2005; Rieppo et al., 2009; Hunziker et al., 2002). This network transitions from a predominantly isotropic architecture in immature tissue to the mature arcade-like zonal structure first described by Benninghoff (1925).

Understanding how such compositional (Stockwell, 1970; Bank et al., 1998; Wachtel et al., 1995; Brama et al., 2000) and architectural changes (Rieppo et al., 2009; Julkunen et al., 2010; Hyttinen et al., 2009) alter the mechanical properties of articular cartilage during postnatal development is central to understanding how the tissue achieves its function. Surprisingly, relatively little is known about how the biomechanical properties of articular cartilage evolve during postnatal development and maturation (Brommer et al., 2005; Julkunen et al., 2009; Williamson et al., 2001). In terms of bulk mechanical properties, an increase in tensile stiffness has been reported with maturation (Williamson et al., 2003; Roth and Mow, 1980), with more subtle changes reported in the compressive properties of the tissue with age (Brommer et al., 2005; Williamson et al., 2001; Julkunen et al., 2009). However, articular cartilage is known to possess complex depthdependent mechanical properties (Wang et al., 2002; Wang and Mow, 1998; Schinagl et al., 1997; Klein et al., 2007), 
which cannot be evaluated through commonly used bulk mechanical testing protocols. Given that articular cartilage changes from a relatively isotropic and homogeneous tissue at 4 weeks postnatal to one displaying significant complexity in its spatial composition and organisation at adulthood, it would seem reasonable to assume that the depth-dependent mechanical properties of the tissue change dramatically during postnatal development. Recently, digital image correlation techniques have been developed to characterise the depth varying compressive properties of articular cartilage (Schinagl et al., 1997; Schinagl et al., 1996; Wang et al., 2002; Canal Guterl et al., 2010). Furthermore, developments such as helium ion microscopy have enabled unprecedented nanoscale visualisation of the collagen network of articular cartilage (Vanden Berg-Foels et al., 2012), while advances in constitutive modelling are providing greater insight into how the structure and composition of articular cartilage determine the biomechanical function of the tissue (Ateshian, 2009; Korhonen et al., 2003; Nagel and Kelly, 2010; Soltz and Ateshian, 2000; Soulhat et al., 1999; Wilson et al., 2007). The objective of this study was to elucidate how the structure and composition of articular cartilage change during postnatal development and maturation using a novel combination of histological, biochemical and imaging techniques, and to relate this evolution to changes in the depth dependent mechanical properties of the tissue. It is envisioned that such knowledge will be integral to the development of novel tissue engineering strategies to successfully regenerate articular cartilage.

\section{Materials and Methods}

\section{Sample preparation}

Tissue explants were isolated and stored as described previously (Gannon et al., 2012). Osteochondral cores (Ø $6 \mathrm{~mm}$ ) were harvested from the femoropatellar groove of healthy porcine knee joints within $3 \mathrm{~h}$ of sacrifice. The porcine model was chosen, as biochemical levels are reported of a similar order of magnitude to human articular cartilage (Malda et al., 2013; Schlichting et al., 2014). Specimens collected were divided into groups, representing different stages of postnatal development: 4 week and 8 week old, immature articular cartilage; 1 year old, approaching skeletal maturity; and 3 years old, representing fully mature articular cartilage. Two pigs from each age group were used. Therefore, a total of eight pigs were used for this study. Three cores from each pig were prepared for mechanical testing to produce 6 samples (for each age group) to account for any variability associated with different anatomical locations and donor-to-donor differences. All cores tested mechanically were then used for biochemical analysis with an additional twenty cores; with at least two cores (from different pigs) added to each respective age group (minimum $n=8$ per age group). Two cores from each animal per age group were chosen for helium ion microscopy ( $n=4$ per age group); and finally two cores from each animal within each age group were chosen for histological analysis. Specimens harvested for mechanical testing were placed in phosphate buffered saline (PBS) solution and stored at $-80{ }^{\circ} \mathrm{C}$ until the day of use. On each respective day of mechanical testing, cores were thawed to room temperature by immersion in PBS and sub-punched from $\varnothing 6 \mathrm{~mm}$ to $\varnothing 3 \mathrm{~mm}$. These cores were then sliced in half to create two semi-cylindrical osteochondral specimens in order to obtain a flat surface on which to image cells (that acted as fiducial markers) within the mechanically compressed tissue. The annulus of each sample was wet weighed and frozen at $-80^{\circ} \mathrm{C}$ for later biochemical analysis. The fiducial markers were created by fluorescent staining of chondrocyte DNA. Chondrocytes are essentially affixed within the dense extracellular matrix because they are three orders of magnitude larger than the effective pore size of the matrix (Maroudas, 1979) and the movement of these cells can thus reflect the deformation of the sample within the imaging plane (Wang et al., 2002). Samples were immersed in $1 \mathrm{~mL}$ PBS with $5 \mu \mathrm{L} /$ $\mathrm{mL}$ Hoechst 33342 for $1.5 \mathrm{~h}$ at $22{ }^{\circ} \mathrm{C}$ to allow diffusion of the dye into the cartilage and reaction with the cellular DNA (Schinagl et al., 1996).

\section{Mechanical testing protocol}

Semi-cylindrical samples of articular cartilage from different stages of postnatal development were tested in unconfined compression in a custom made stainless steel compression rig (Fig. 1) that was designed to sit on the stage of an inverted fluorescent Olympus IX 51 microscope equipped with a $100 \mathrm{~W}$ xenon arc lamp, a DAPI filter cube and a 0.4 NA Universal Plan Super Apochromat $10 \times$ objective (Mason Technology, Dublin, Ireland). The semi-cylindrical cartilage sample was bathed in PBS in a testing chamber with a glass microscopic slide window at its base, sandwiched between two Perspex loading platens with its rectangular cross section facing down toward the microscope objective; enabling the visualisation of the tissue during testing. Compression was manually applied to the articular surface of test specimens by advancement of a micrometer gauge attached to the remaining Perspex platen (Mitutoyo, Radionics, Dublin, Ireland; resolution $0.01 \mathrm{~mm}$ ). The remaining platen was rigidly connected to a precision miniature load cell (Model 31, 10 lbs., RDP Electronics Ltd., Wolverhampton, UK); amplified by a 4-Ch 24-Bit Full Bridge Analogue Input (NI 9237, National Instruments UK \& Ireland, Berkshire, UK) and connected to a standard laptop (Dell XPS M1330; Intel Core 2 Duo Processor) interfaced using LabView software (National Instruments UK \& Ireland). Images were recorded with a 12-bit Olympus DP70 camera (Mason Technology; view $1360 \times 1024)$ and Analysis imaging software (Mason Technology). The $1360 \times 1024$ pixel image represented a $583 \times 438 \mu \mathrm{m}$ sampling of the specimen focal plane at $0.428 \mu \mathrm{m} /$ pixel.

Cartilage thickness was determined using bright field microscopy at $4 \times$ magnification in the uncompressed state (Chen et al., 2001). A tare load of $\sim 1 \mathrm{~N}$ was applied to ensure union between the platen and the articular surface after which the sample was allowed to fully relax. The samples were compressed up to $10 \%$, in $2.5 \%$ strain increments, and then to $15 \%$ and $20 \%$ offset strain based on the initial sample thickness determined after tare load application at a strain rate of $0.5 \% / \mathrm{s}$. After each 

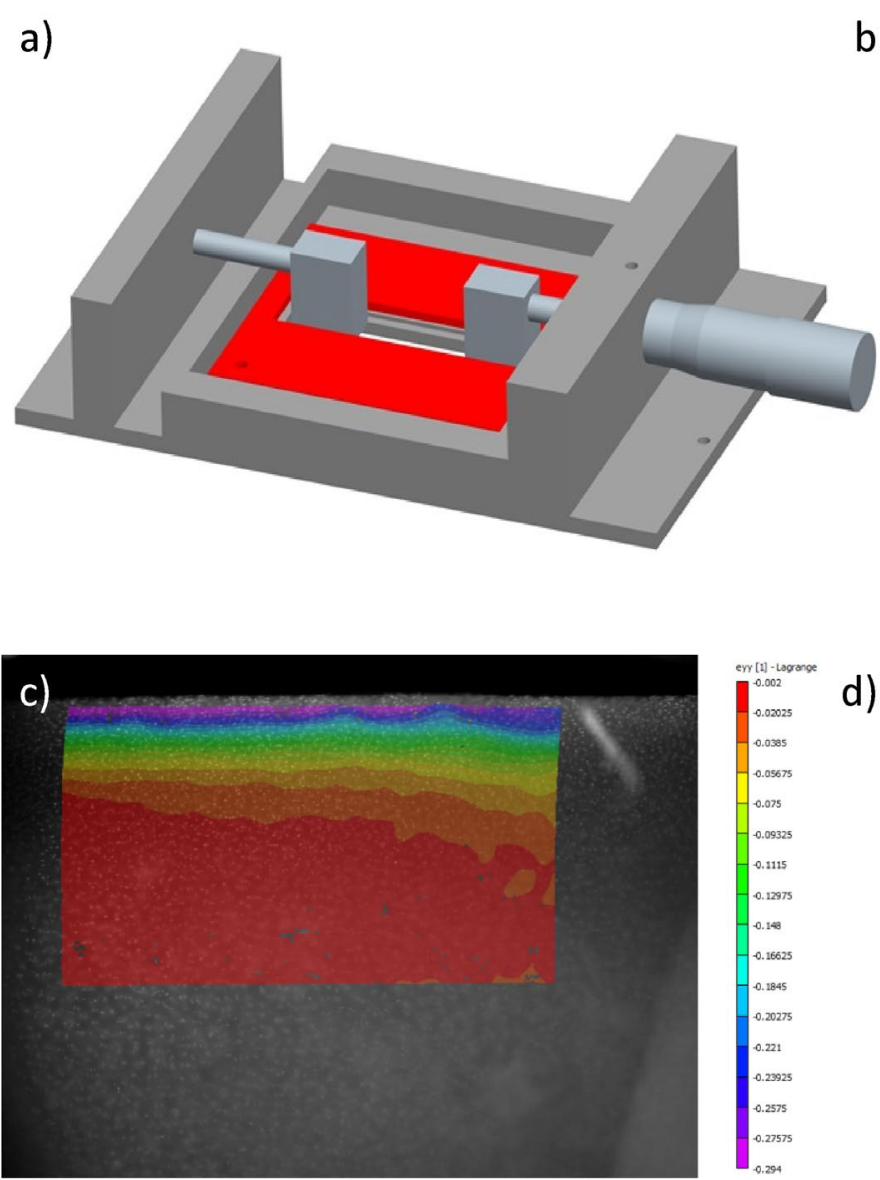

b)

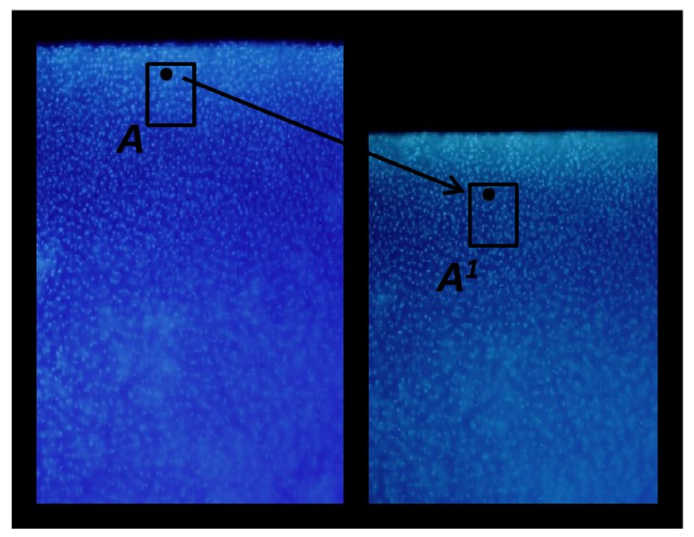

Undeformed

Deformed

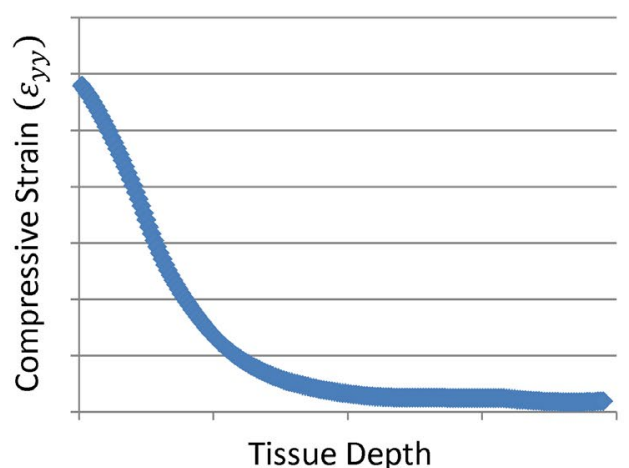

Fig. 1. (a) Schematic of custom designed unconfined compression rig, (b) example of an undeformed reference and subsequently deformed fluorescent image taken prior to and after loading illustrating the way in which strain is tracked at every loading increment, (c) example of a typical strain $\left(\varepsilon_{y y}\right)$ correlation for a one year old sample for a selected region of interest (ROI), (d) graphical representation of the strain output of image (c) displayed as the compressive strain in the zonal direction $\left(\varepsilon_{y y}\right)$ plotted versus depth from the articular surface (pixels).

loading increment the sample was allowed to relax for $60 \mathrm{~min}$ or until the stress changed by less than $0.001 \mathrm{MPa}$ in 5 min (Chen et al., 2001), and the equilibrium force was measured. The intra tissue displacement field was calculated using the digital image correlation software VIC 2D 2009 (Correlated Solutions, Columbia, SC, USA). The average axial $\left(\varepsilon_{y y}\right)$, lateral $\left(\varepsilon_{x x}\right)$ and shear strain $\left(\varepsilon_{x y}\right)$ were computed within three distinct zones; the superficial tangential zone (STZ), the middle zone (MZ) and the deep zone (DZ). These regions were assumed to be $0-6 \%$, $7-18 \%$ and $19-30 \%$, respectively, of the total cartilage thickness from the articular surface. Zone thicknesses were determined in the referential configuration and then followed throughout the deformation. Local strains were computed for a range of different global offset strains $(2.5 \%, 5 \%, 10 \%$ and $15 \%$ strain), from which the depth dependent nominal equilibrium Young's modulus $\left(E_{y y}\right)$ and Poisson's ratio were determined. The depth dependent nominal Young's modulus $\left(E_{y y}, \mathrm{MPa}\right)$ was taken as the equilibrium force, divided by the specimens cross-sectional area, divided by the computed averaged strain $\left(\varepsilon_{v y}\right)$ within each zone for each nominal applied global offset strain. Likewise, Poisson's ratio was calculated as the negative ratio of averaged strain in the radial direction $\left(\varepsilon_{x x}\right)$ to the averaged axial strain $\left(\varepsilon_{y y}\right)$, all computed for each applied global offset strain; $2.5 \%, 5 \%, 10 \%$ and $15 \%$ strain.

\section{Biochemical analysis}

The wet mass of all annuli of the mechanically tested cores were recorded and the samples were frozen for subsequent biochemical analysis as mentioned previously. The frozen samples were freeze dried (RVT4104 Thermo Scientific, Hemel Hempstead, UK) for 48 h or until a constant dry weight was obtained. The samples were then recovered, weighed and sub-divided to yield separate aliquots for sulphated GAG, collagen content and cross-link analyses.

\section{Sulphated glycosaminoglycan determination}

Aliquots of dry material $(\sim 10 \mathrm{mg})$ were placed in $1 \mathrm{~mL}$ $50 \mathrm{mM}$ phosphate buffer, $2 \mathrm{mM}$ EDTA, pH 6.5 (Sigma, Gillingham, UK) and hydrated overnight. Samples were then digested with papain $0.5 \mathrm{~mL}(0.5 \mathrm{mg} / \mathrm{mL})$ at $60{ }^{\circ} \mathrm{C}$ under constant rotation for $18 \mathrm{~h}$. The proteoglycan content was determined by quantifying the amount of sulphated GAG using the dimethylmethylene blue dye-binding assay (Sigma Aldrich, Gillingham, UK), in comparison with a chondroitin sulphate standard (Farndale et al., 1982). Data were normalised to the tissue dry weight and wet weight. 
Table 1. Specific cross-linking data for all measured time points; four weeks, eight weeks, one year and three years old.

\begin{tabular}{|l|c|c|c|c|}
\hline \multicolumn{1}{|c|}{ Cross-Link $^{\mathbf{1}}$} & 4 Weeks. & 8 Weeks. & 1 Year. & 3 Years. \\
\hline OHPyr (mol/ mol) & $0.339044 \pm 0.021$ & $0.347882 \pm 0.014$ & $0.426479 \pm 0.021$ & $0.415663 \pm 0.021$ \\
\hline LysPyr (mol / mol) & $5.372473 \pm 0.384$ & $4.263293 \pm 0.529$ & $3.257847 \pm 0.200$ & $3.921245 \pm 0.355$ \\
\hline HHL (mol / mol) & $0.010926 \pm 0.001$ & $0.013906 \pm 0.001$ & $0.020964 \pm 0.002$ & $0.019304 \pm 0.002$ \\
\hline HKLNL (mol / mol) & $0.23215 \pm 0.052$ & $0.137895 \pm 0.025$ & $0.025400 \pm 0.007$ & $0.029725 \pm 0.008$ \\
\hline HLNL (mol /mol) & $0.031619 \pm 0.006$ & $0.043163 \pm 0.003$ & $0.053693 \pm 0.003$ & $0.044065 \pm 0.003$ \\
\hline
\end{tabular}

${ }^{1}$ The mature cross-links are hydroxylysyl pyridinoline (OHPyr), lysyl pyridinoline (LysPyr) and histidinohydroxylysinonorleucine (HHL), whilst the immature cross-links are hydroxylysino-ketonorleucine (HLKNL) and hydroxylysinonorleucine (HLNL). Cross-links are expressed as moles of crosslink per mole of collagen; data is presented as mean with SEM.

\section{Collagen cross-link determination}

The samples were rehydrated with phosphate buffered saline overnight at $4{ }^{\circ} \mathrm{C}$, then treated with sodium borohydride as described elsewhere (Avery et al., 2009). After $1 \mathrm{~h}$ reduction at room temperature they were acid hydrolysed for $24 \mathrm{~h}$ at $115^{\circ} \mathrm{C}$, lyophilised and prefractionated using strong cation exchange solid phase extraction (SPE) cartridges (Biotage Ltd, Kungsgatan, Sweden), prior to cross-link analysis. Cross-links were quantified using a Dionex Ultimate 3000 auto-sampler (Thermo Scientific) linked to a Dionex ICS 3000 ion chromatography system (Thermo Scientific) configured for post-column analysis of the eluate from a $15 \times 0.46 \mathrm{~cm}$ sodium cation exchange column (Pickering Laboratories, Mountain View, CA, USA). Column eluate was reacted with ninhydrin in a post column reactor at $125{ }^{\circ} \mathrm{C}$ (CRX400, Pickering Laboratories) and assayed using a variable wavelength detector set at $570 \mathrm{~nm}$ (Dionex Ultimate 3000, Thermo Scientific). System control and data acquisition was by means of Dionex Chromeleon software. The cross-links were quantified; by comparison with standards prepared in-house, after resolution using an analytical program also developed in-house. The mature cross-links hydroxylysyl pyridinoline, lysyl pyridinoline and histidinohydroxylysinonorleucine could all be detected, although lysyl pyridinoline predominated in all samples. The immature cross-links hydroxylysinoketonorleucine and hydroxylysinonorleucine were also detected in some samples but at appreciably lower levels (Table 1). Cross-links are expressed as moles of crosslink per mole of collagen.

\section{Hydroxyproline analysis}

Prior to treatment with SPE an aliquot $(5 \mu \mathrm{L})$ of the above hydrolysates was analysed for hydroxyproline content (Burkhard Scientific, Uxbridge, UK) utilising the Bannister and Burns adaptation (Bannister and Burns, 1970) of the Bergman and Loxley technique (Bergman and Loxley, 1963). Total collagen content was determined by assuming a hydroxyproline conversion factor of 7.15 (Etherington and Sims, 1981). Data acquisition and manipulation was by means of Dionex AI 450 software. Data were normalised to the tissue dry weight and wet weight.
Histological analysis, polarised light microscopy and helium ion microscopy

Depth dependent sulphated GAG and collagen content were determined histologically; as described previously (Gannon et al., 2012). Briefly, sections were stained with safranin $\mathrm{O}$ for $\mathrm{sGAG}$ and picrosirius red for collagen and subsequently imaged on an Olympus Bx41 microscope equipped with a 30-bit CCD camera (Mason Technology).

In order to visualise the orientation of the collagen fibril architecture, picrosirius red stained sections were imaged using a polarised light microscope (Nikon Eclipse E400 POL) (Gannon et al., 2012). In an effort to enhance visualisation of the collagen architecture, all sulphated glycosaminoglycans were removed from the tissue sections by bovine testicular hyaluronidase (Sigma) treatment for $18 \mathrm{~h}$. The enzyme was prepared in $0.1 \mathrm{M}$ phosphate buffer, $\mathrm{pH} 6.9$, containing hyaluronidase $1000 \mathrm{U} \mathrm{mL}^{-1}$ at $37^{\circ} \mathrm{C}$ (Király et al., 1997).

In addition, the collagen network was imaged using a helium ion microscope (HIM) (Orion ${ }^{\circledR}$ Plus, Carl Zeiss NTS) with an Everhart-Thornley detector producing an image from the secondary electrons generated by the incident helium ions. In order to provide an unobstructed view of the collagen fibrils, serial enzymatic digestion was used to remove glycosaminoglycan from the cartilage specimens; this protocol is based on a modified version of Vanden Berg-Foels et al. (2012). HIM images were acquired in secondary electron mode with an acceleration voltage of $34.9 \mathrm{kV}$, a beam current of 0.2-0.5 pA and a dwell time of $0.5-2.0 \mu \mathrm{s}$. High resolution images were acquired in the superficial zone of the articular cartilage (classified as the top $100 \mu \mathrm{m}$ of tissue from the articular surface), in the middle zone (taken between 100-250 $\mu \mathrm{m}$ from the articular surface) and in the deep zone (taken below $500 \mu \mathrm{m}$ from the articular surface) across age groups, in order to visualise the changing morphology of individual network fibrils and fibril connections in these regions of the tissue during skeletal maturation. In the 4 week old and 8 week old immature tissue samples an extra region was imaged, due to the increased thickness of the immature samples; this region was labelled the lower deep zone and taken as approximately $1 \mathrm{~mm}$ from the articular surface. All images were acquired using a pixel resolution of $2048 \times 2048$ 
or $1024 \times 1024$. The pixel spacing for a $1 \mu \mathrm{m}$ field of view corresponds to a pixel dimension spacing of 0.49 $0.98 \mathrm{~nm} /$ pixel. The brightness and contrast of all images were optimised; no other post processing procedures were performed. Fibril diameters were measured using ImageJ (Schneider et al., 2012).

\section{Constitutive model}

The effects of collagen network stiffness and alignment on the bulk mechanical properties of a cartilage sample in unconfined compression cannot be clearly separated experimentally. The interpretation of experimental results is additionally complicated by variations in other tissue properties, such as porosity and fixed charge density to name but a few. Therefore, a set of simulations was performed in which changing bulk mechanical properties could be attributed to isolated and controlled variations of collagen network stiffness and orientation.

A finite strain biphasic material model with a Donnan osmotic swelling pressure was implemented, where the solid matrix was modelled as an overlay of a NeoHookean component and several families of fibrils (Görke et al., 2010). To capture both isotropic and anisotropic fibril distributions, the fibril network was modelled as consisting of a quasi-isotropic network of 7 secondary and, in the case of anisotropy, additionally 2 primary families of fibrils (Wilson et al., 2005). In models with an isotropic fibril arrangement, the overall collagen network stiffness was equally distributed among the 7 secondary fibrils. In simulations with anisotropic fibril architectures, the primary and secondary fibrils were assigned weights according to Wilson et al. (2005), such that the primary fibrils forming the characteristic Benninghoff architecture were significantly stiffer than the secondary isotropic network. Independent of the architecture, the overall fibril stiffness (sum over all families) was kept constant. As was performed previously (Nagel and Kelly, 2010), a Holzapfel-type free energy functional (Holzapfel et al., 2000) was used as a constitutive model for the individual fibrils. The fibril stiffness values were determined as described by Nagel and Kelly (2010) (Table 2).

The described model was implemented into the source code of FEBio (version 1.6.1, (Maas et al., 2012)). After a free swelling step, steady state unconfined compression tests were simulated by lowering a frictionless contact platen onto the surface of the cartilage plug. To mimic the presence of the bone, displacements at the cartilage-bone interface were constrained in all directions. Lateral surfaces were traction-free and were assigned homogeneous Dirichlet boundary conditions for the pore pressure. Local Young's moduli were predicted in the superficial, middle and deep regions of the tissue. The model was used to investigate the relative influence of the changing collagen fibril stiffness and collagen network orientation on the compressive properties of articular cartilage during postnatal development. Average homogeneous material properties for the porosity $(80 \%)$ and the fixed charge density $\left(0.0002 \mathrm{mEq} / \mathrm{mm}^{3}\right)$ were used for all models, while sample geometry was kept constant. Isotropic and Benninghoff fibril architectures were investigated using either baseline fibril stiffness values or with a significantly increased fibril stiffness (to account for increases due to higher collagen content and increased collagen crosslinking). The parameter values for the constitutive model are listed in Table 2, and for the performed simulations with varied collagen network properties see Table 3 .

\section{Statistical analysis}

Statistical analysis was performed using a general linear model for analysis of variance with Tukey's post-hoc test for multiple comparisons used to compare regional/zonal differences and age affects. All tests were performed using the statistical software package MINITAB 15.1 (Minitab Ltd., Coventry, UK). Graphical and numerical results are displayed as mean with standard error. Significance was accepted at $p \leq 0.05$ or as indicated. Sample numbers varied according to respective comparison and are outlined in the methods section of this manuscript.

Table 2. Free Helmholtz energy potentials and parameter values used in the constitutive model. Details regarding model formulation and implementation as well as parameter identification can be found in the references quoted in the text.

\begin{tabular}{|c|c|c|c|c|c|}
\hline Component & \multicolumn{5}{|c|}{ Equation and parameter values } \\
\hline \multirow{2}{*}{ Neo Hooke } & \multicolumn{5}{|c|}{$\psi_{N H}=C_{10}(\boldsymbol{I}: \boldsymbol{C}-\ln (\operatorname{det} \boldsymbol{C})-3)+D_{2}(\ln (\operatorname{det} \boldsymbol{C}))^{2}$} \\
\hline & \multicolumn{2}{|c|}{$C_{10}=0.1 \mathrm{MPa}$} & \multicolumn{3}{|c|}{$D_{2}=0.0063 \mathrm{MPa}$} \\
\hline \multirow{2}{*}{ Holzapfel } & \multicolumn{5}{|c|}{$\psi_{f}=\frac{C_{4}}{2 \beta}\left[\exp \left(\beta(\boldsymbol{I}: \boldsymbol{M C}-1)^{2}\right)-1\right]$} \\
\hline & \multicolumn{2}{|c|}{$C_{4}=3.0 \mathrm{MPa}($ see table 3$)$} & \multicolumn{3}{|c|}{$\beta \rightarrow 0$} \\
\hline \multirow{2}{*}{ Donnan } & \multicolumn{2}{|c|}{$\psi_{o s m}=R T c_{F 0} \phi_{F 0}$} & $\frac{2 c_{e x t}}{c_{F}}-\frac{\sqrt{4 c_{e x t}^{2}+c_{F}^{2}}}{c_{F}}+\operatorname{arcsinh} \frac{c_{F}}{2 c_{e x t}}$ & \multicolumn{2}{|c|}{ with $c_{F}=\frac{c_{F 0} \phi_{F 0}}{\sqrt{\operatorname{det} C}-1+\phi_{F 0}}$} \\
\hline & $R=8.314 \frac{\mathrm{J}}{\mathrm{mol} \mathrm{K}}$ & $T=298 \mathrm{~K}$ & $c_{F 0}=0.0002 \frac{\mathrm{mEq}}{\mathrm{mm}^{3}}$ & $c_{\text {ext }}=0.00015 \frac{\mathrm{mEq}}{\mathrm{mm}^{3}}$ & $\phi_{F 0}=0.8$ \\
\hline
\end{tabular}


Table 3. Acronyms of the performed simulations along with the collagen network architecture and the fibre stiffness values. The Benninghoff architecture was modelled as described in the text and the references quoted therein.

\begin{tabular}{|l|c|c|c|}
\hline Simulation name & Fibre architecture & Primary fibril stiffness & Secondary fibril stiffness \\
\hline ISO LOW & Isotropic & -- & $C_{4 i}=0.429 \mathrm{MPa}$ \\
\hline ISO HIGH & Isotropic & -- & $C_{4 i}=1.287 \mathrm{MPa}$ \\
\hline BENN LOW & Benninghoff & $C_{4 i}=1.161 \mathrm{MPa}$ & $C_{4 i}=0.097 \mathrm{MPa}$ \\
\hline BENN HIGH & Benninghoff & $C_{4 i}=3.483 \mathrm{MPa}$ & $C_{4 i}=0.291 \mathrm{MPa}$ \\
\hline
\end{tabular}

2.5\% Applied Strain

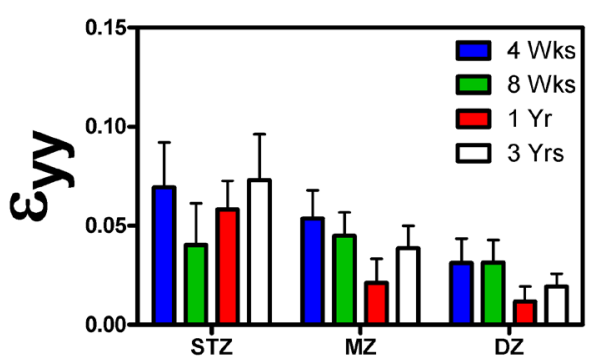

$10 \%$ Applied Strain

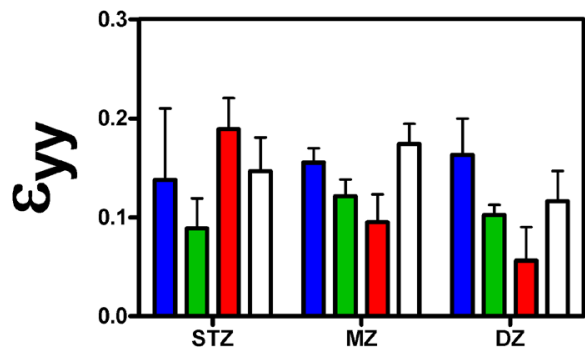

$5 \%$ Applied Strain

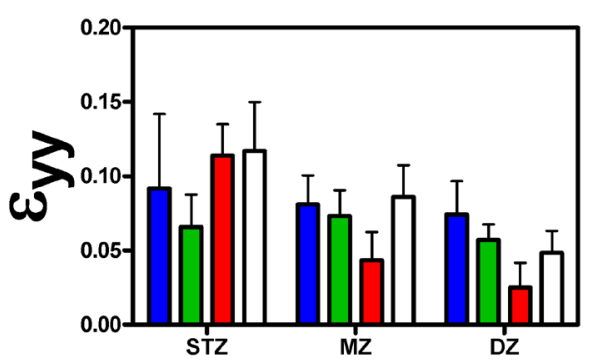

15\% Applied Strain

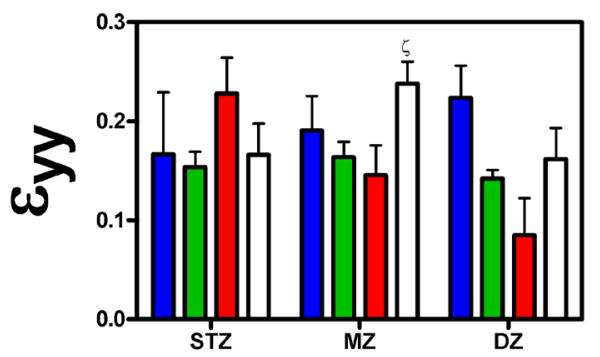

Fig. 2. Compressive strain $\left(\varepsilon_{v y}\right)$ in the zonal direction plotted versus depth from the articular surface divided into three distinct zones - the superficial tangential zone (STZ), the middle zone (MZ) and the deep zone (DZ). The results displayed are of different stages of postnatal development: 4 weeks old, 8 weeks old, one year old and three years old. In addition, the graphs are displayed at increasing global offset strains: $2.5 \%, 5 \%, 10 \%$ and $15 \%$. Bars show mean with SEM; statistical significance is taken at $p \leq 0.05$. $\varsigma$ indicates significant difference $v s .1$ year DZ.

\section{Results}

Dramatic changes to the depth dependent mechanical properties of articular cartilage are observed during postnatal development and skeletal maturation

The average local strain $\left(\varepsilon_{v y}\right)$ in the superficial tangential zone (STZ), middle zone (MZ) and deep zone (DZ) of porcine articular cartilage (from 4 week old, 8 week old, one year old and three year old donors) was determined using digital image correlation (DIC) for increasing magnitudes of global applied strain $(2.5 \%, 5 \%, 10 \%$ and $15 \%$ ). Similar local strains were measured through the depth of the 4 week old and 8 week old tissues (Fig. 2). In contrast, local strains were found to significantly $(p<0.05)$ depend on depth within the 1 year old mature tissue, with lower strains measured in the deeper regions of the tissue compared to the STZ. These spatial strain measurements were then used to compute the local Young's modulus through the depth of the tissue with age. No significant changes in the local Young's moduli $\left(E_{y y}\right)$ were observed with depth from the articular surface in 4 week old and 8 week old immature articular cartilage (Fig. 3), irrespective of the applied global strain. In contrast, the DZ was found to be significantly stiffer than the STZ in one year old cartilage for all applied strains. In addition, significant differences were observed between the depth dependent mechanical properties of the immature (4 weeks old) and skeletally mature ( 1 and 3 year old) tissue, with dramatic increases observed in the Young's modulus of the DZ of articular cartilage during postnatal development. For example, at low global offset strains (2.5\% applied strain), the DZ of the one year old $(6.01 \pm 1.35 \mathrm{MPa})$ and three year old $(9.4 \pm 4.07 \mathrm{MPa})$ tissues were significantly stiffer than corresponding region in the 4 week old $(0.97 \pm 0.45 \mathrm{MPa})$ tissue ( $p=0.0315$ and $p=0.0052$, respectively). At high global offset strains (15\% global applied strain), all regions of the three year old tissue (STZ, MZ and DZ: $1.1 \pm 0.18 \mathrm{MPa}, 0.97 \pm 0.15 \mathrm{MPa}$ and $1.92 \pm 0.57 \mathrm{MPa})$ were significantly stiffer than the immature 4 week old (STZ, MZ and DZ: $0.33 \pm 0.06 \mathrm{MPa}, 0.27 \pm 0.04 \mathrm{MPa}$ and $0.28 \pm 0.1 \mathrm{MPa}$ ) tissue $(p=0.0133, p=0.0019$ and $p<0.0001$, respectively). Similarly, the DZ of the one 


\section{5\% Applied Strain}

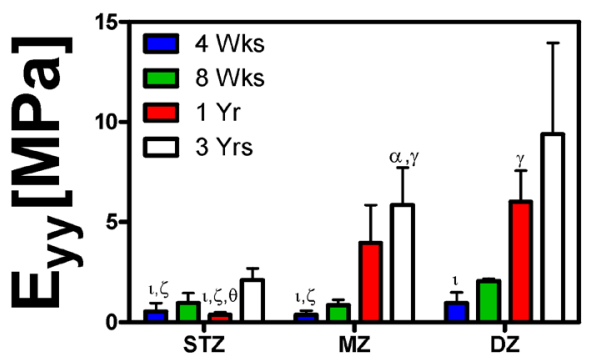

10\% Applied Strain

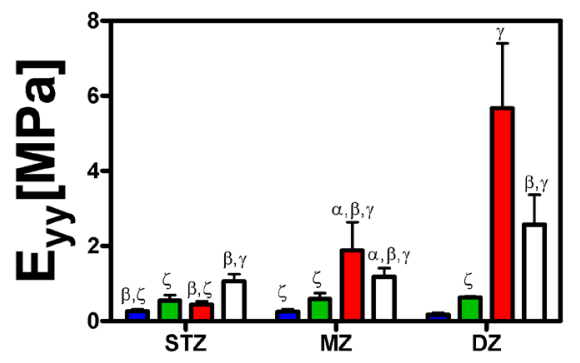

5\% Applied Strain

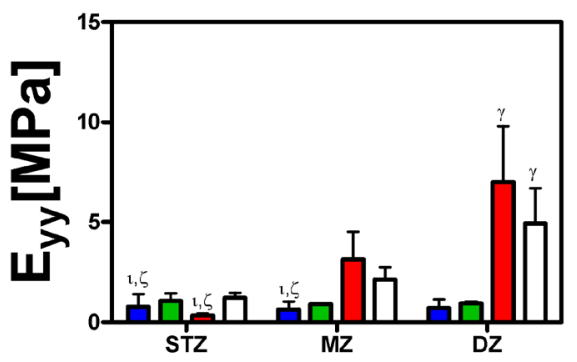

15\% Applied Strain

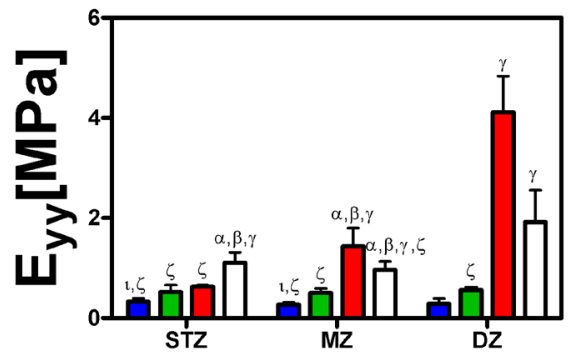

Fig. 3. Incremental Young's modulus, $\left(E_{y y}\right)(\mathrm{MPa})$, in the zonal direction plotted versus depth from the articular surface divided into three distinct zones - the superficial tangential zone (STZ), the middle zone (MZ) and the deep zone (DZ). The results displayed are of different stages of postnatal development: 4 weeks old, 8 weeks old, one year old and three years old. In addition, the graphs are displayed at increasing global offset strains: $2.5 \%, 5 \%, 10 \%$ and $15 \%$. Bars show mean with SEM; statistical significance is taken at $p \leq 0.05$. Statistical differences are indicated as follows: $\alpha$ vs. 4 weeks $S T Z, \beta$ vs. 4 weeks $M Z$, $\gamma$ vs. 4 weeks DZ, s vs. 1 year DZ, $\theta$ vs. 3 years MZ, l vs. 3 years DZ.

2.5\% Applied Strain

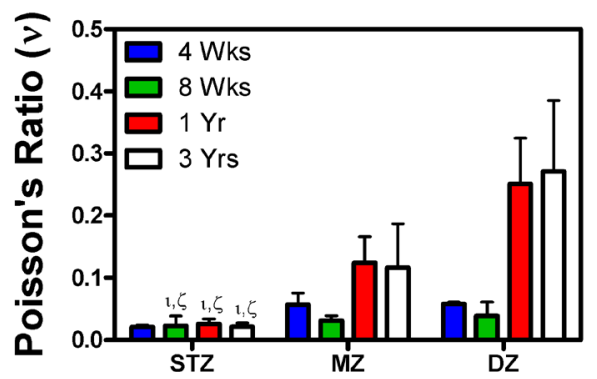

10\% Applied Strain

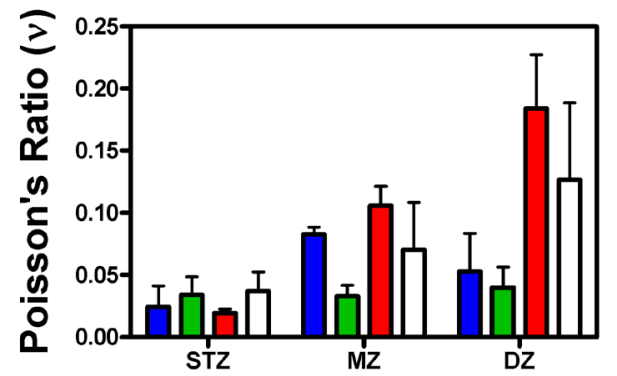

5\% Applied Strain

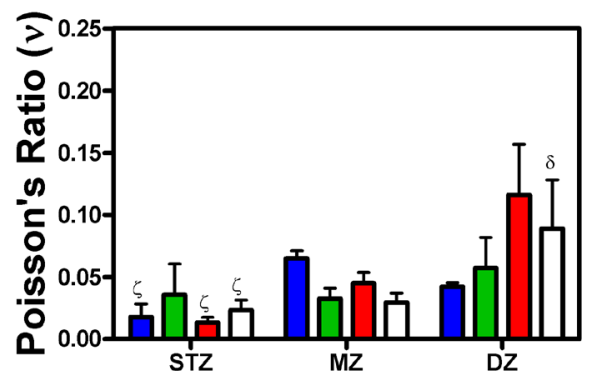

15\% Applied Strain

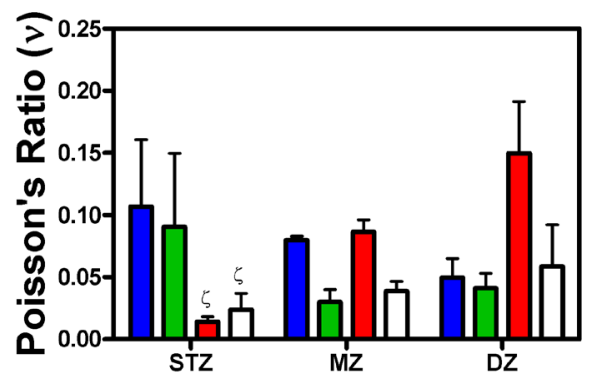

Fig. 4. Poisson's ratio $v$ in the zonal direction plotted versus depth from the articular surface divided into three distinct zones - the superficial tangential zone (STZ), the middle zone (MZ) and the deep zone (DZ). The results displayed are of different stages of postnatal development: 4 weeks old, 8 weeks old, one year old and three years old. In addition, the graphs are displayed at increasing global offset strains: $2.5 \%, 5 \%, 10 \%$ and $15 \%$. Bars show mean with SEM; statistical significance is taken at $p \leq 0.05$. Statistically significant differences are indicated as follows: $\delta$ vs. 1 year $S T Z$, s vs. 1 year DZ, $\theta$ vs. 3 years $M Z$, v vs. 3 years $D Z$. 


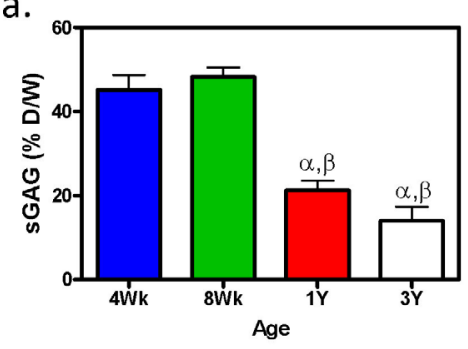

C.

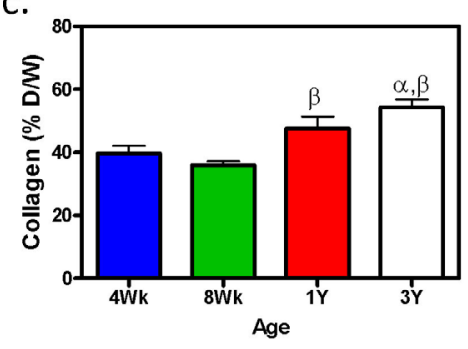

e.

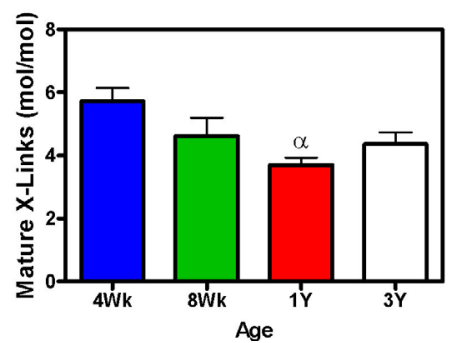

b.

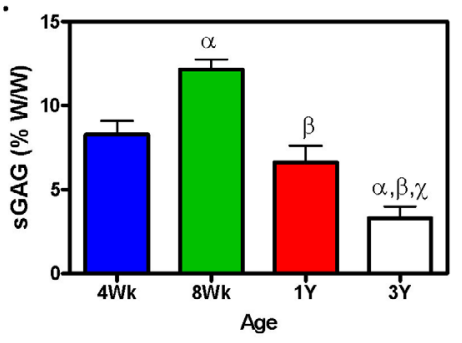

d.

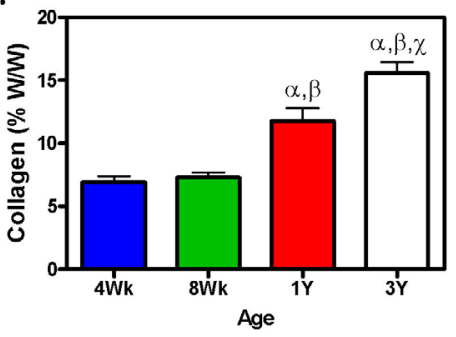

f.

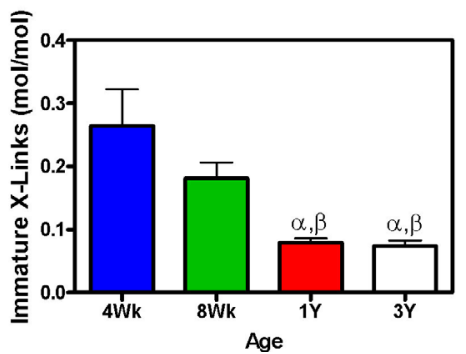

g.

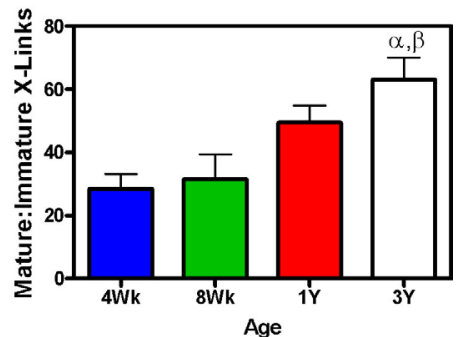

Fig. 5. (a) Sulphated glycosaminoglycan (sGAG) content expressed per sample dry weight (\%), (b) sGAG content expressed per sample wet weight $(\%),(\mathbf{c})$ total collagen content expressed per sample dry weight $(\%),(\mathbf{d})$ total collagen content expressed per sample wet weight (\%), (e) mature collagen cross-links expressed as moles cross-link per mole of collagen ( $\mathrm{mol} / \mathrm{mol})$, (f) immature collagen cross-links expressed as moles cross-link per mole of collagen (mol/ mol), (g) the ratio of mature collagen cross-links to immature collagen cross-links. All samples are full thickness articular cartilage cores obtained from developing age groups: 4 weeks old, 8 weeks old, one year old and three years old. Bars show mean with SEM; statistical significance is taken at $p \leq 0.05$. Statistical differences are indicated as follows: $\alpha$ vs. 4 weeks, $\beta$ vs. 8 weeks, $\chi$ vs. 1 year.

year old tissue $(6.01 \pm 1.35,7 \pm 2.42,5.68 \pm 1.49$ and $4.1 \pm 0.63 \mathrm{MPa}$ for $2.5 \%, 5 \%, 10 \%$ and $15 \%$ strain, respectively) was significantly stiffer than DZ of the 4 week old $(0.97 \pm 0.45,0.71 \pm 0.38,0.17 \pm 0.05$ and $0.28 \pm 0.1 \mathrm{MPa}$ for $2.5 \%, 5 \%, 10 \%$ and $15 \%$ strain, respectively) tissue ( $p=0.0315, p=0.0084, p<0.0001$ and $p<0.0001)$ for all applied strains.

A noticeable reduction in Young's moduli $\left(E_{y y}\right)$ of the DZ was observed with increasing level of applied strain (termed strain softening), particularly for skeletally mature tissue. For example, the Young's modulus of the $\mathrm{DZ}$ of the three year old articular cartilage was observed to decrease from approximately $10 \mathrm{MPa}$ (at $2.5 \%$ applied stain) to $2 \mathrm{MPa}$ (at $15 \%$ applied strain). Less dramatic strain softening was observed in the immature tissue. No significant differences in Poisson's ratio (calculated as the negative ratio of the transverse strain $\left(\varepsilon_{x x}\right)$ to the axial strain $\left(\varepsilon_{y y}\right)$ when loaded in the axial direction) with location (i.e. with depth or zone) was observed for immature tissue (Fig. 4). In contrast, at low offset strains the Poisson's ratio of the STZ of the one and three year old tissues $(0.026 \pm 0.007$ and $0.021 \pm 0.006)$ were significantly $(p=0.047$ and $p=0.0034)$ smaller than their respective $\mathrm{DZ}(0.25 \pm 0.06$, $0.27 \pm 0.1)$. Whilst at high strains (15\% global applied strain), the Poisson's ratio of the STZ of the one year old tissue $(0.014 \pm 0.003)$ was significantly $(p=0.017)$ smaller than in the DZ $(0.15 \pm 0.04)$.

\section{Increases in tissue compressive properties with age are accompanied by a reduction in the sGAG content and an increase in collagen content}

We next sought to determine if the observed increases in tissue mechanical properties with age correlated with changes in the sGAG and collagen content and collagen crosslinking. Biochemical analysis revealed a significant decrease $(p<0.0001)$ in sGAG content with age when normalised to percentage dry weight (Fig. 5). The one year and three year old mature tissues contained significantly less sGAG than the four week old ( $p=0.0016$ and $p=0.0001$, respectively) and 8 week old $(p=0.0009$ and $p<0.0001$, respectively) immature tissue also when normalised to percentage wet weight. Overall collagen content significantly increased with age $(p<0.0001)$. The mature three year old tissue contained significantly higher 

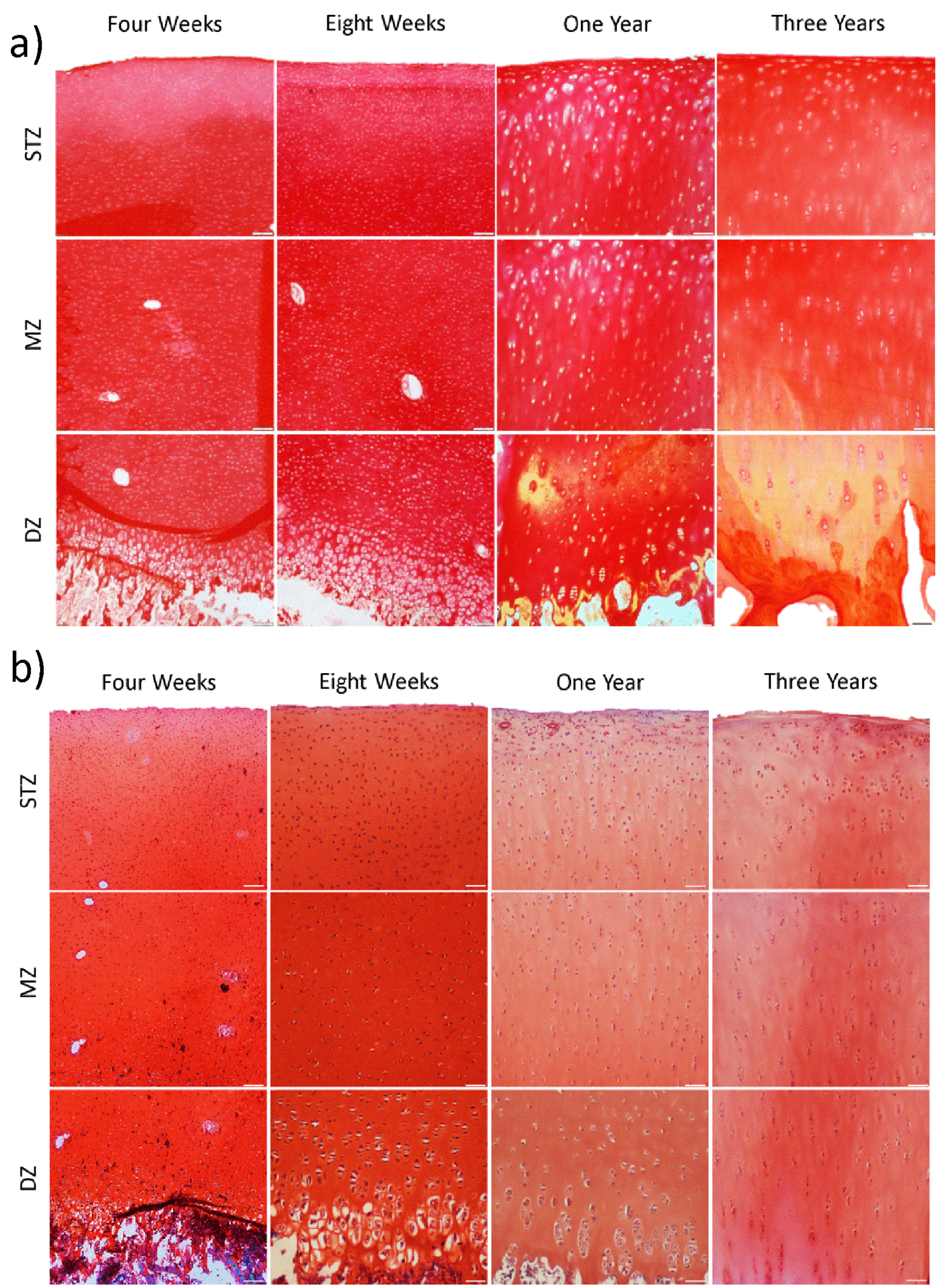

Fig. 6. Full thickness cartilage sections stained with picrosirius red-collagen (a) and safranin O-sGAG (b) from the femoral trochlear ridges. Images are taken at each respective zone - STZ, MZ and DZ with developing ages; four weeks, eight weeks, one year and three years old. Scale bars $100 \mu \mathrm{m}$. 

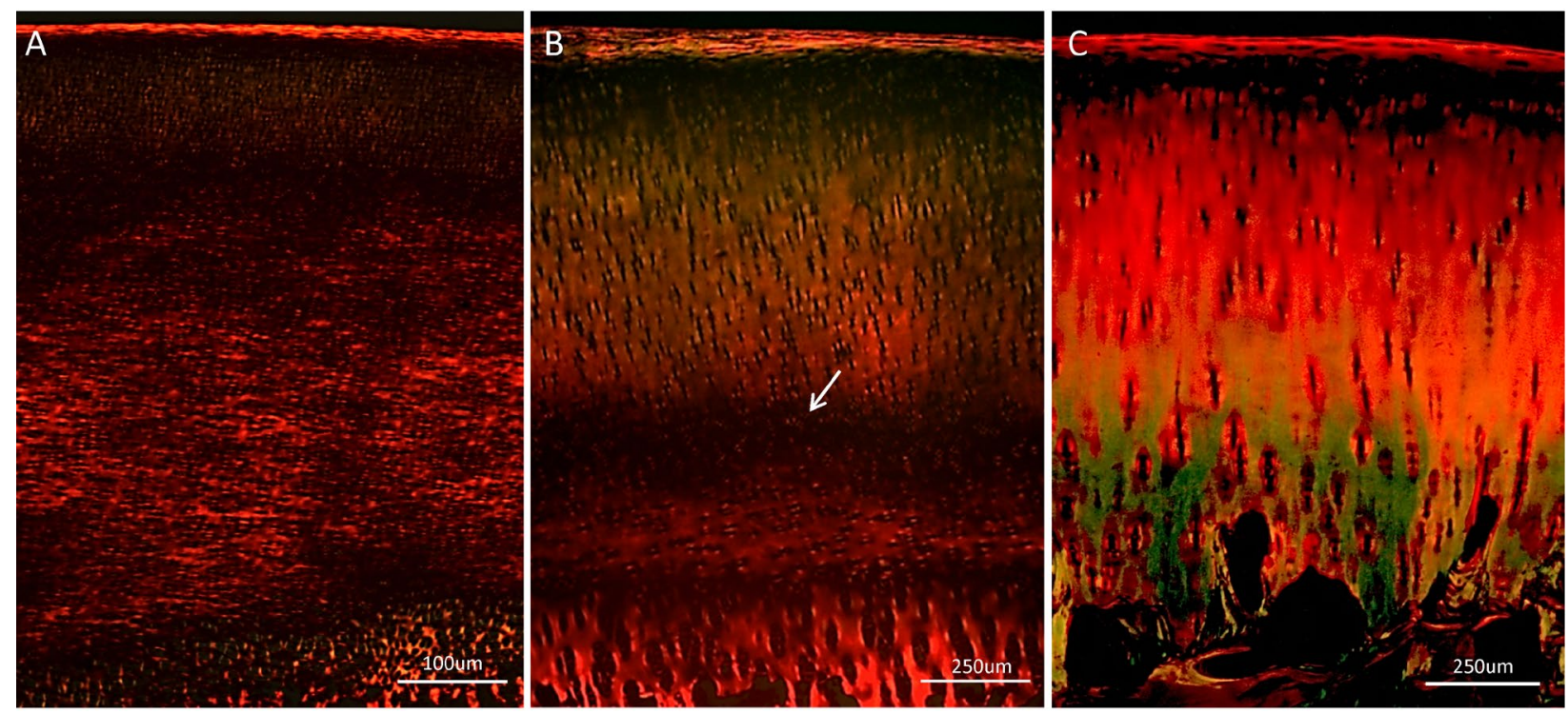

Fig. 7. Polarised light microscopic images outlining the different stages of development of the collagen architecture; 4 week old (A), one year old (B) and three year old (C). Arrow indicates an extra lamina or zone within the deep zone of the one year old tissue. Scale bar in image (A) is $100 \mu \mathrm{m}$; scale bars in images (B) and (C) are $250 \mu \mathrm{m}$.

amounts of collagen compared to the $4(p=0.0016)$ and 8 week old tissue $(p<0.0001)$ (Fig. 5); this was also seen when normalised to percentage wet weight. A significant decrease in immature cross-links was also observed with skeletal development ( $p=0.001)$, with the one year and three year old tissues containing significantly lower amounts of immature collagen cross-links than the 4 week $(p=0.0018$ and $p=0.0002)$ and 8 week $(p=0.036$ and $p=0.004$ ) old immature tissue. In addition, the ratio of mature to immature cross-links was significantly higher in the mature three year old tissue compared to the 4 week and 8 week old immature tissues ( $p=0.0036$ and $p=0.0087$, respectively). Aside from these changes in biochemical composition, the thickness of articular cartilage was found to significantly $(p<0.0001)$ decrease with age (4 week old, $4.4895 \pm 0.22 \mathrm{~mm}$; 8 week old, $2.9863 \pm 0.11 \mathrm{~mm}$; one year old, $1.0578 \pm 0.06 \mathrm{~mm}$; three years old, $0.8747 \pm 0.02 \mathrm{~mm}$ ).

Histological analysis was also undertaken to help identify if the spatial composition of articular cartilage changes during postnatal development (Fig. 6). Picrosirius red-stained sections (Fig. 6a) point to an increase in staining between the 4 week and 8 week old immature and the 1 year and 3 year old mature tissues, whilst safranin O staining (Fig. 6b) demonstrated a decrease in staining between the immature and mature samples. However, no dramatic differences in either safranin $\mathrm{O}$ or picrosirius red staining was observed with depth, suggesting that spatial changes in tissue composition with age cannot fully explain the increase in compressive stiffness observed with skeletal maturation.

\section{Increases in the depth-dependent mechanical} properties of articular cartilage are accompanied by significant changes in collagen fibril alignment and fibril diameter

Polarised light microscopy (PLM) was first undertaken to help elucidate the time point during skeletal development at which a Benninghoff-like collagen architecture emerges in articular cartilage (Fig. 7). With PLM, large bands of vivid colour known as birefringence indicate extensive degrees of alignment; this can be clearly visualised in the three year old fully mature tissue, which demonstrates clear evidence of such organisation in the superficial tangential zone and in the deep zone of the tissue. In stark contrast, very little evidence of organisation was observed in the immature 4 week old tissue, bar a thin band of organised fibrils in the superficial region (Fig. 7). In the one year old cartilage, where the tissue is beginning to reach skeletal maturity (i.e. closure of the epiphyseal growth plate), the collagen architecture had transitioned from a predominantly isotropic structure observed in the immature cartilage towards an adult phenotype. An extra lamina was also present in the lower part of the deep zone, as evidenced by a region of the tissue displaying a decrease in birefringence (and hence a decrease in the degree of organisation in this region of the tissue). This extra lamina may highlight the process of internal reorganisation of the tissue (Nieminen et al., 2002; Rieppo et al., 2009; Hunziker et al., 2007) from a predominantly isotropic structure in immature articular cartilage to a highly organised Benninghoff architecture present in fully mature tissue.

Helium ion microscopy was used to visualise how the morphology of the collagen network fibrils and fibrillar connections of articular cartilage adapt with age and spatially through the tissue. No clear spatial changes in structural organisation with depth were observed in the immature 4 week old and 8 week old tissues (Fig. 8). In the superficial tangential zone $(100 \mu \mathrm{m}$ from the articular surface), the collagen fibrils lacked any preferential arrangement. Similarly, no evidence of collagen fibril alignment was observed in the middle zone, the upper portion of the deep zone or the lower portion of the deep zone at these time points. In addition, fibrils and fibrillar connections were abundant in their numbers throughout the 
Four Week Old

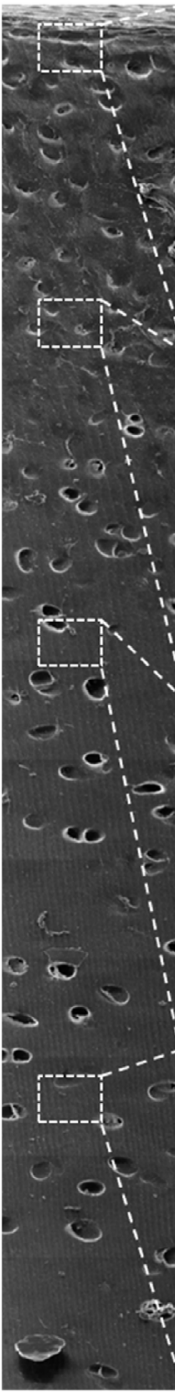

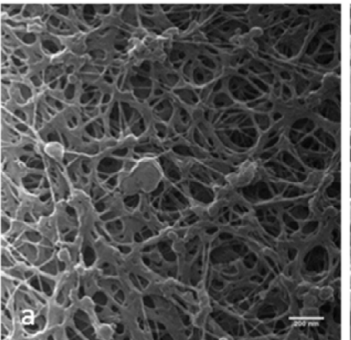
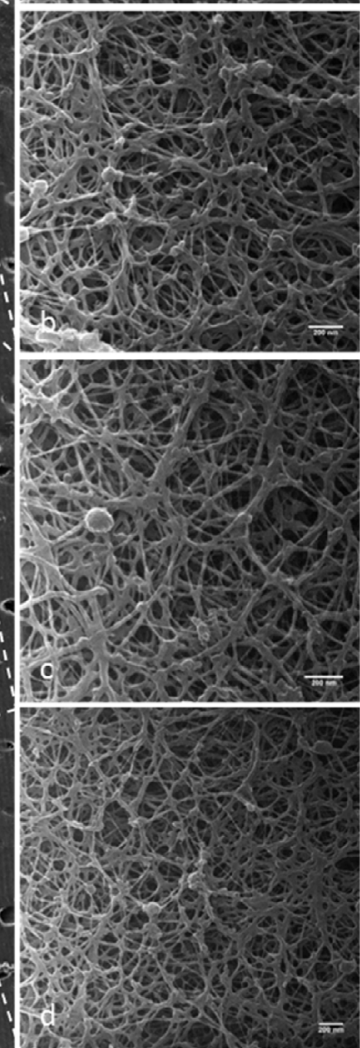
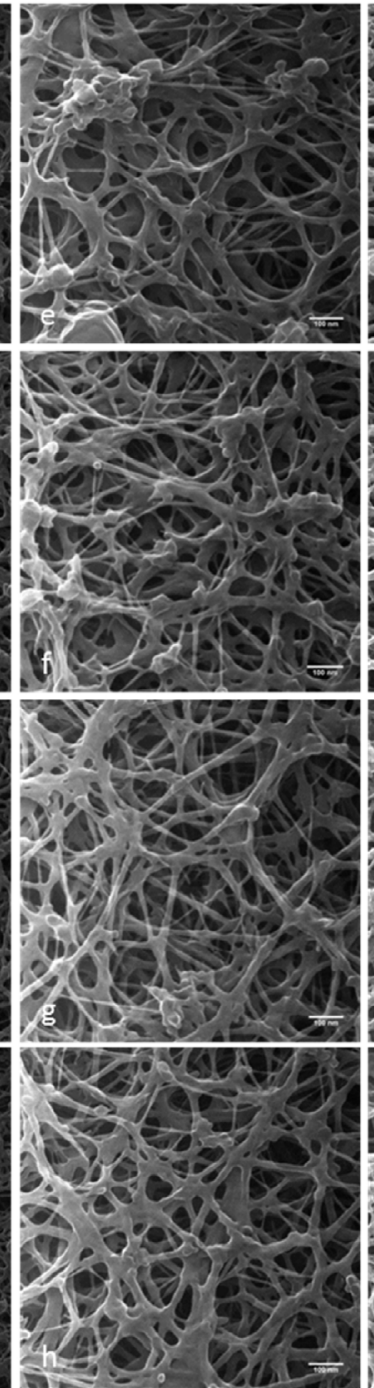

Eight Week Old
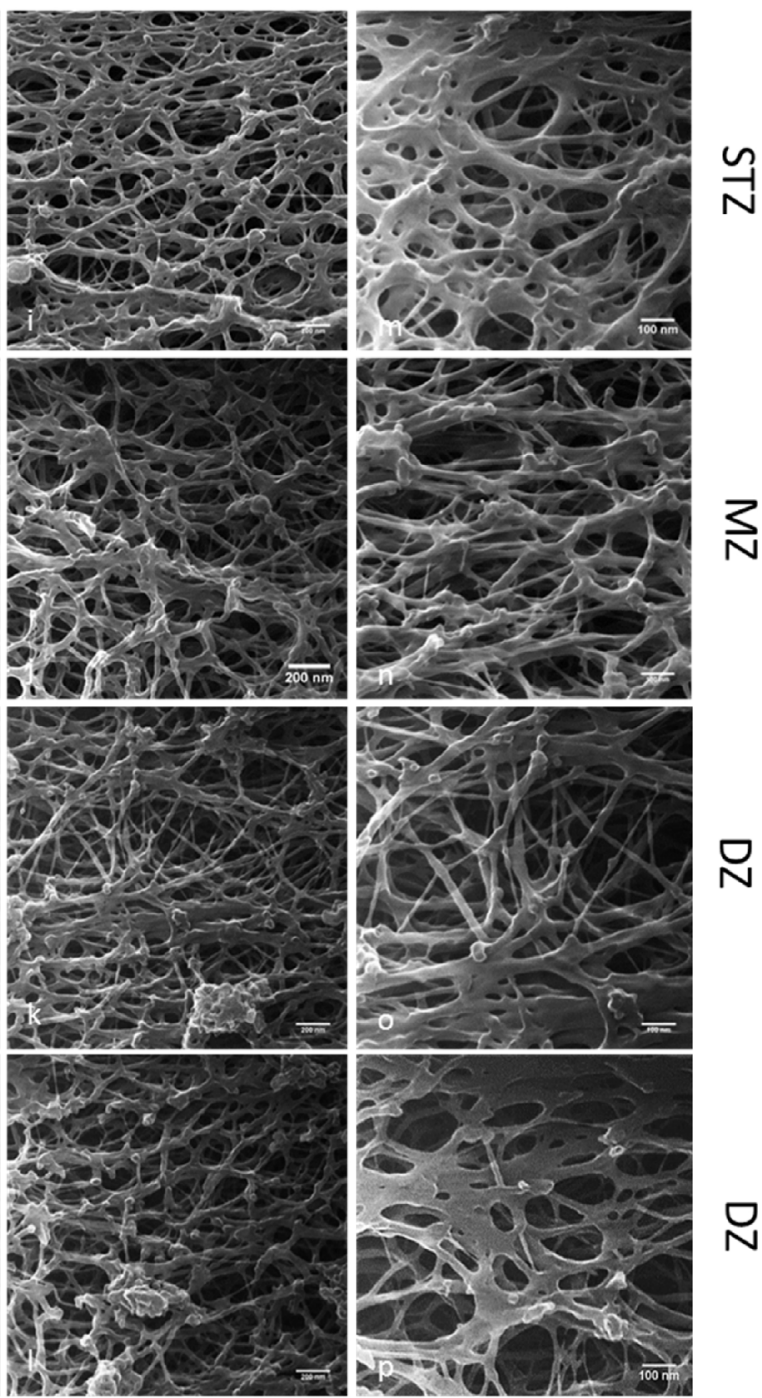

Fig. 8. Helium ion microscopic images of 4 week old immature collagen architecture (vertically: a-h) and 8 week old immature collagen architecture (vertically: i-p) taken from different zonal depths from the articular surface; the superficial tangential zone (horizontally: a,e,i,m), the middle zone (horizontally: $\mathbf{b}, \mathbf{f}, \mathbf{j}, \mathbf{n}$ ), the upper deep zone (horizontally: c,g,k,o), and the lower deep zone (horizontally: d,h,l,p). Scale bar is $200 \mathrm{~nm}$ on images a-d and i-l; scale bar is $100 \mathrm{~nm}$ on images $\mathbf{e - h}$ and $\mathbf{m}$-p).

immature tissues. In contrast, in the one year old tissue (Fig. 9) the collagen fibrils appeared more structured in their organisation. In the superficial tangential zone, the collagen fibrils appeared to be arranged into bundles or groups of fibrils. These bundles, in turn, were predominantly aligned parallel to the articular surface. Within these fibril bundles certain individual collagen fibrils still appeared crimped and randomly orientated, which may be due, at least in part, to proteoglycan removal during tissue processing for helium ion microscopy. In the middle zone, the collagen fibrils arcaded from a predominantly parallel orientation at the articular surface to a perpendicular orientation in the deep zone, thus resulting in a more random organisation. In the deep zone the collagen fibrils were predominantly arranged perpendicular to the articular surface. A classical Benninghoff architecture was most apparent in the fully mature three year old articular cartilage (Fig. 9). Collagen fibrils were organised parallel to the articular surface in the superficial tangential zone and arcaded to a perpendicular arrangement in the deep zone. Fewer fibrils and fibrillar connections were also seen in both the one year old and three year old tissues. In addition, an increase in fibril diameter was observed with both age and depth from the articular surface (Fig. 10). In the superficial zone, average fibril diameter increased significantly from approximately $11 \pm 0.99 \mathrm{~nm}$ in the 4 week old tissue to $78 \pm 9.05 \mathrm{~nm}$ in the three year old tissue $(p<0.0001)$. In the middle zone, average fibril diameter increased from approximately $20 \pm 1.92 \mathrm{~nm}$ in the 4 week old tissue to $125 \pm 7.8 \mathrm{~nm}$ in the mature tissue $(p<0.0001)$. Finally, in the deep zone average fibril diameter increased from approximately $21 \pm 1.39 \mathrm{~nm}$ in the 4 week old tissue to $151 \pm 24.47 \mathrm{~nm}$ in the three year old fully mature tissue $(p<0.0001)$. These findings also demonstrate that more dramatic differences 


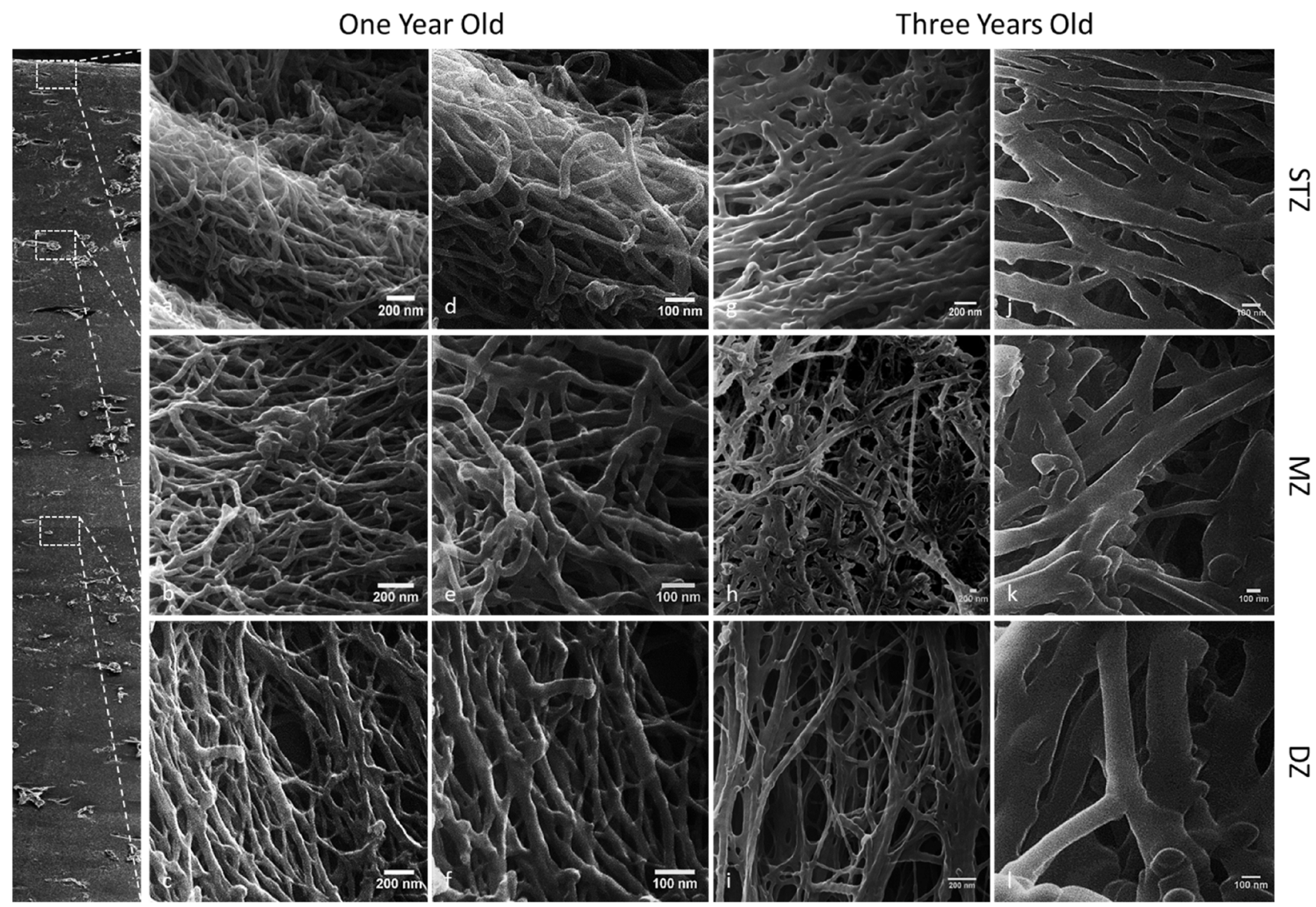

Fig. 9. Helium ion microscopic images of one year old collagen architecture (vertically: a-f) and three year old mature collagen architecture (vertically: g-l) taken from different zonal depths from the articular surface; the superficial tangential zone (horizontally: a,d,g,j), the middle zone (horizontally: b,e,h,k), the deep zone (horizontally: $\mathbf{c , f}, \mathbf{i}, \mathbf{l} \mathbf{l})$. Scale bar is $200 \mathrm{~nm}$ on images a-c and $\mathbf{g - i}$ ); scale bar is $100 \mathrm{~nm}$ on images $\mathbf{d - f}$ and $\mathbf{j}-\mathbf{l}$ ).

in collagen fibril diameter with depth occur in the fully mature tissue.

\section{Both collagen network realignment and stiffening with age are predicted to contribute to increases in tissue compressive properties}

The above results demonstrate that the alignment of the collagen network of articular cartilage adapts with skeletal maturation. Furthermore, the inherent stiffness of the collagen network will also presumably increase due to increases in the tissue collagen content, increases in collagen fibril diameter and increases in the ratio of mature to immature collagen cross-links. The next phase of this study therefore sought to determine the relative impact that both of these changes (i.e. collagen 'stiffening' and 'realignment') will have, in isolation, on the compressive stiffness of the tissue. To this end, a finite strain biphasic constitutive model of articular cartilage that incorporated Donnan osmotic swelling pressure effects was employed. The collagen fibril alignment (either 'isotropic' or 'Benninghoff-like') and collagen fibril stiffness (either 'low' or 'high') were varied, while all other material properties in the model were kept constant. Increasing the stiffness of the collagen fibril network, or introducing a Benninghoff-like collagen architecture, was found to have the greatest impact on the model predictions of Young's moduli at low applied strains (Fig. 11). Here, increasing the collagen fibril stiffness in isolation was predicted to lead to a 2.5-fold increase in the compressive modulus in the $\mathrm{DZ}$ of the tissue from 2.9 $\mathrm{MPa}$ to $7.15 \mathrm{MPa}$. Introducing a Benninghoff-like collagen architecture, whilst maintaining low fibril stiffness, was predicted to lead to a 3-fold increase in the Young's modulus in the DZ of the tissue to $9.3 \mathrm{MPa}$ at low applied strains. Increasing the collagen fibril stiffness and introducing a Benninghoff-type architecture was predicted to lead to a synergistic increase in compressive stiffness, increasing 8-fold to $24.3 \mathrm{MPa}$ at low applied strains. Dramatic strain softening was predicted in the DZ of the Benninghoff model that incorporated high fibril stiffness, and to a lesser extent in the Benninghoff model that incorporated low fibril stiffness. At high offset strains, no dramatic difference in compressive Young's modulus was observed between the four groups. This phenomenon was not observed experimentally. As might be expected, increasing the stiffness of the collagen network in isolation did not lead to a prediction of depth dependent Poisson's ratio. In contrast, the experimentally observed increase in Poisson's ratio with depth in the mature tissue was predicted once the Benninghoff collagen architecture was incorporated into the model (data not shown). 


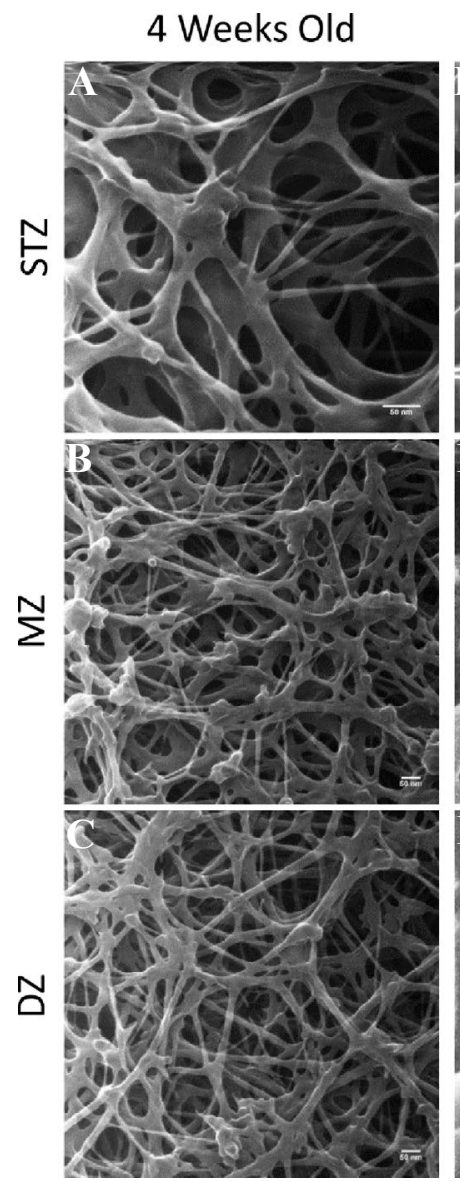
Three Years Old
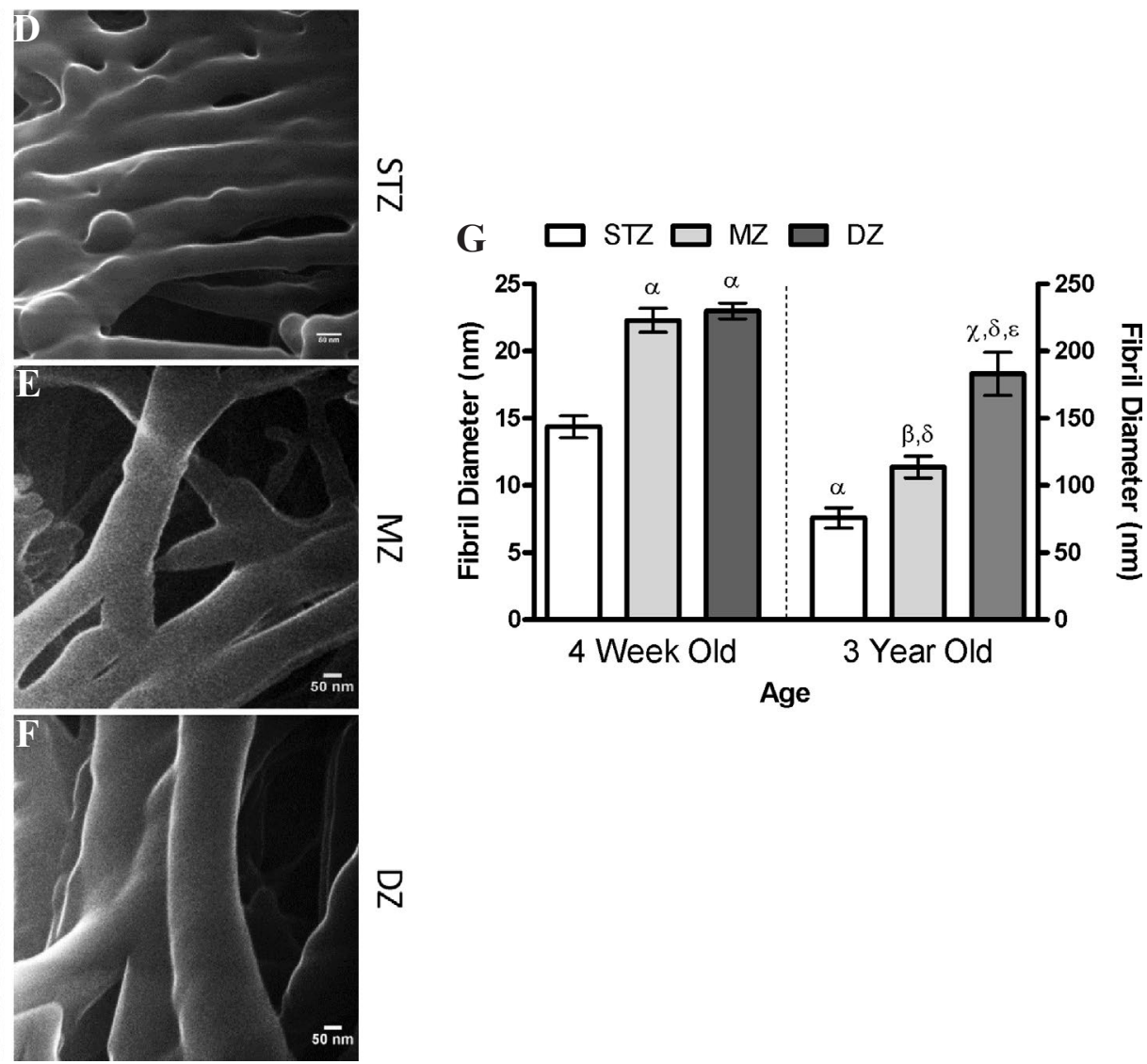

Fig. 10. Helium ion microscopic images of 4 week old immature collagen fibrils (A-C) and three year old mature collagen fibrils (D-F) taken from different zonal depths from the articular surface; the superficial tangential zone $(\mathbf{A}, \mathbf{D})$, the middle zone $(\mathbf{B}, \mathbf{E})$ and the deep zone $(\mathbf{C}, \mathbf{F})$. Scale bar is $50 \mathrm{~nm}$. (G) Graph of fibril diameters (nm) across age groups and zones - STZ, MZ and DZ. Bars show mean with SEM; statistical significance is taken at $p \leq 0.05$. Statistical differences are indicated as follows: $\alpha$ vs. 4 weeks STZ, $\beta$ vs. 4 weeks $M Z, \chi$ vs. 4 weeks DZ, $\delta$ vs. 3 years $S T Z$, \& vs. 3 years DZ.
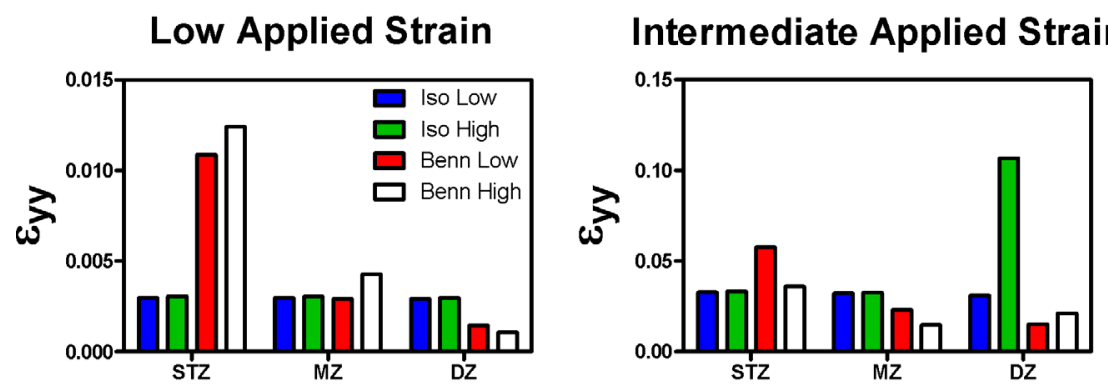

High Applied Strain
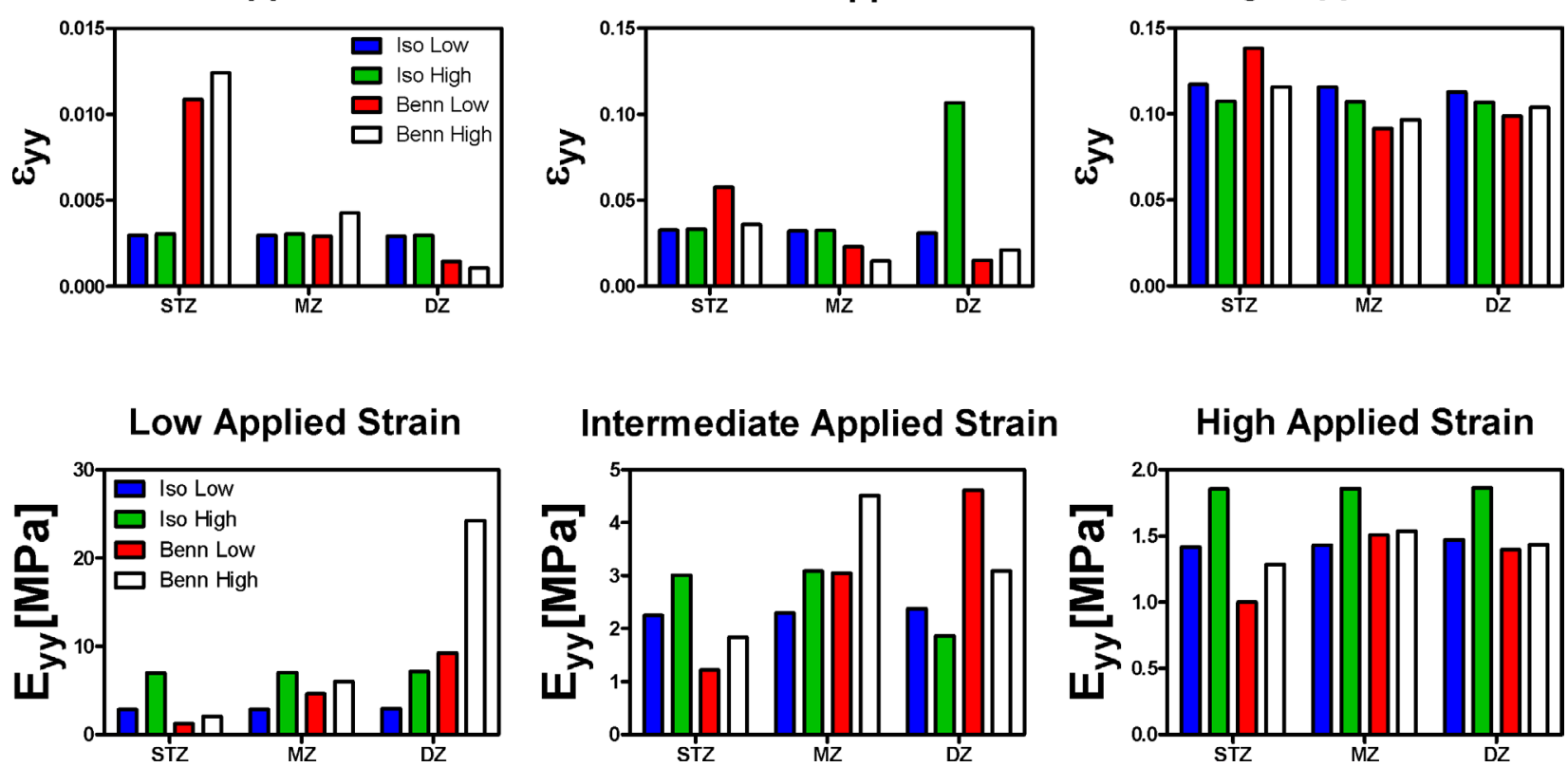

High Applied Strain
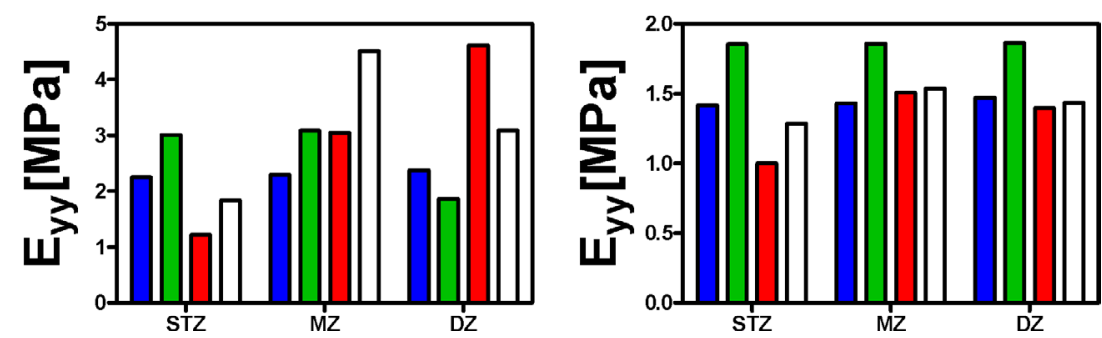

Fig. 11. Model predictions of compressive strain in the zonal direction $\left(\varepsilon_{y y}\right)$ and incremental Young's modulus, $\left(E_{y y}\right)$ (MPa), plotted for specific zones in articular cartilage (STZ, MZ and DZ) at increasing levels of applied strain (low, intermediate and high) of four different groups (Iso Low, Iso High, Benn Low and Benn High). The zonal analysis of the simulation results followed the same procedure as in the experimental part of the study. 


\section{Discussion}

The aim of this study was to investigate how changes to the structure, composition and organisation of articular cartilage from 4 weeks postnatal to skeletal maturity influence the depth dependent mechanical properties of the tissue. Dramatic increases in Young's modulus with depth from the articular surface were observed in the one year old and three year old mature tissues, whilst less significant changes in Young's modulus with depth were observed in the 4 week and 8 week old tissues. This increase in stiffness with depth has traditionally been associated with spatial changes in tissue sulphated GAG content, resulting in higher fixed charge densities with depth, which generate greater Donnan osmotic fluid pressures (Ateshian, 2009). The most dramatic changes that occurred with age were in the deep zone of articular cartilage, where an order of magnitude increase in the compressive properties of the tissue (for low offset strains) was observed from 4 weeks postnatal to skeletal maturity. Remarkably, this occurred despite the fact that the sGAG content of articular cartilage was observed to decrease with maturity. These findings suggested that changes to the composition and organisation of the collagen network of articular cartilage with skeletal development instead play the dominant role in determining the final compressive mechanical properties of the tissue.

To further explore this possibility, we utilised a range of biochemical assays and microscopy tools to probe how the collagen network of articular cartilage adapts from 4 weeks postnatal to skeletal maturity. Polarised light microscopy revealed substantial reorganisation of the tissue had occurred in both the one year and three year old tissues compared to the immature tissue which was primarily isotropic in structure. The mature tissue had attained what is known as a Benninghoff architecture, where the collagen fibrils are orientated parallel to the articular surface in the superficial tangential zone and perpendicular to the subchondral bone in the deep zone of the tissue. In addition, helium ion microscopy demonstrated a significant increase in collagen fibril diameter, which was accompanied by an increase in collagen content and a maturation of the collagen cross-links during postnatal development. Taken together, these results strongly suggest that the collagen network of articular cartilage both stiffens and reorganises with age. The dramatic increase in deep zone compressive modulus with age $(\sim 10$-fold increase in the DZ from 4 weeks to 3 years at low offset strains) can be related to these changes to the collagen network. Specifically, swelling pressures generated by negatively charged proteoglycans put this collagen network into a state of tension in the absence of external loads (Chahine et al., 2004; Khalsa and Eisenberg, 1997). The stiffer pre-stressed collagen fibrils aligned parallel to the direction of loading in mature tissue will provide greater resistance to axial compressive loading at low strains compared to the less stiff unaligned fibrils in immature cartilage (Nagel and Kelly, 2010), which explains the increased Young's modulus in the deep zone of the mature tissue compared to the immature tissue.

In order to elucidate the relative contribution of both collagen network reorganisation and stiffening on the compressive properties of the tissue, a finite strain biphasic material model with a Donnan osmotic swelling pressure was employed. In this framework, a model with an isotropic, low stiffness collagen network was considered similar to the immature tissue, whilst the model with a fully developed Benninghoff architecture and high collagen fibril stiffness was considered representative of the skeletally mature tissue in terms of structure. These model predictions provide further support for our hypothesis that changes to the collagen network, in isolation, can explain the dramatic increases observed in the compressive properties of articular cartilage during postnatal development. In particular, the dramatic increases in DZ compressive modulus that are observed with age are predicted by a model that includes both a Benninghoff architecture and a stiff fibril collagen network (specifically, a prediction of a $\sim 8$-fold increase in stiffness at low offset strains compared to a tissue modelled with an isotropic structure and a low fibril stiffness). A noticeable difference between experimental and model predications was that the model did not predict any differences in the compressive modulus in the DZ of the tissue for high offset strains, which were not observed experimentally. The model was set up to help us understand the impact of collagen network properties, in isolation, and as such had to exclude the impact of variations in other tissue properties (e.g. porosity, fixed charge density) which are likely relevant for a more accurate representation of compressive properties at higher strains. Therefore, certain compositional or organisational changes occurring in articular cartilage with age are not captured by the model. Besides this point, the simple Neo-Hookean model used for the ground substance is not predictive of the complex behaviour of the tissue at high strains.

Another noticeable difference in the mechanical behaviour of immature and mature tissue was the greater levels of strain softening observed during compressive loading of the mature tissue. While such strain softening has been observed previously in articular cartilage (Chahine et al., 2004; Schinagl et al., 1997; Wang et al., 2003), it remains to be elucidated if the emergence of such strain softening properties with age are of functional importance to the tissue. These higher levels of strain softening can also be attributed to the vertical arrangement of the collagen fibrils in the deep zone of the mature tissue (as confirmed by the model simulations). Due to tissue swelling, these fibrils are initially in a state of pre-stress, contributing to tissue compressive properties. However, with increasing applied strains, these vertical fibrils buckle and will no longer contribute to the load bearing capabilities of the tissue to the same degree. Differences were also observed in the strain-softening behaviour between the one year old and three year old tissues, with the latter undergoing more dramatic softening, which again can be attributed to the younger tissue being less organised and less stiff. Indeed, less dramatic strain softening was also predicted in the finite element model that incorporated a Benninghoff-architecture with low fibril stiffness compared to the Benninghoff-like model with high fibril stiffness. With higher fibril stiffness, less tensile strains but higher stresses will be generated within the collagen network in the free swelling state, meaning that more dramatic strain 
softening will occur as the tissue is initially compressed under strain control. The fact that such a phenomenon is more pronounced in the three year old tissue, compared to the one year old tissue, would further suggest that the collagen network of the former is stiffer than the latter.

Due to articular cartilage's poor capacity for repair once damaged, tissue engineering approaches have been pushed to the forefront of new joint regeneration strategies (Kim et al., 2003; Chung and Burdick, 2008; Hunziker, 2002). Recent approaches have attempted to generate complex tissues with zonal cell and tissue phenotypes in order to improve the functional properties of engineered cartilage (Accardi et al., 2013; Klein et al., 2003; Ng et al., 2009; Ng et al., 2005; Sharma et al., 2007; Thorpe et al., 2013; Nguyen et al., 2011; Kock et al., 2013). Despite extensive efforts to replicate the inhomogeneity of mature articular cartilage, these engineered constructs typically possess zonal characteristics that are, at best, similar to immature articular cartilage ( $\mathrm{Ng}$ et al., 2005; Sharma et al., 2007; Klein et al., 2003). In addition, the fact that such in vitro engineered tissues do not possess a Benninghoff-like collagen architecture means that their DZ compressive properties are at least an order of magnitude lower than that of skeletally mature articular cartilage. Engineering a mechanically competent tissue in vitro prior to implantation is clinically relevant, as such functionality may be the key to long-term success ( $\mathrm{Ng}$ et al., 2009; Nagel and Kelly, 2013). Whilst new scaffold fabrication techniques, such as electro-spinning and 3D weaving, have gone some way to generating constructs that mimic certain mechanical characteristics of native articular cartilage (Accardi et al., 2013; Moutos et al., 2007), the unique complexity and functionality of the native tissue have yet to be recapitulated. The novel findings presented in this study highlight the importance of temporal changes to the collagen network of articular cartilage during skeletal maturation for determining the tissue's ability to bear compressive loads. Future tissue engineering strategies should therefore place a greater focus on recapitulating the mechanical functionality associated with the pre-stressed anisotropic collagen architecture of mature tissue in order to regenerate hyaline cartilage.

\section{Conclusions}

Despite decades of research, relatively little is known about how changes to the composition and organisation of articular cartilage with age impact the mechanical functionality of the tissue. This study demonstrates that the compressive stiffness of articular cartilage increases by up to an order of magnitude from 4 weeks postnatal to skeletal maturity. By combining biomechanical and biochemical assays with novel imaging modalities and computational models, we demonstrate that the temporal evolution of the tissue's collagen network plays a significant role in driving the increases in the compressive mechanical properties of the tissue with age. These results suggest that tissueengineering strategies should place a greater focus on recapitulating the mechanical functionality associated with the pre-stressed, anisotropic collagen network of skeletally mature articular cartilage to enable joint regeneration.

\section{Acknowledgements}

This study was funded by the Science Foundation Ireland (SFI) under the President of Ireland Young Researcher Award (PIYRA) 08/YI5/B1336 and IRCSET (G30345). We wish to confirm that there are no known conflicts of interest associated with this publication and there has been no significant financial support for this work that could have influenced its outcome.

\section{References}

Accardi MA, Mccullen SD, Callanan A, Chung S, Cann PM, Stevens MM, Dini D (2013) Effects of fiber orientation on the frictional properties and damage of regenerative articular cartilage surfaces. Tissue Eng Part A 19: 2300-2310.

Ateshian GA (2009) The role of interstitial fluid pressurization in articular cartilage lubrication. J Biomech 42: 1163-1176.

Avery NC, Sims TJ, Bailey AJ (2009) Quantitative determination of collagen cross-links. Methods Mol Biol 522: 103-121.

Bank RA, Bayliss MT, Lafeber FPJG, Maroudas A, Tekoppele JM (1998) Ageing and zonal variation in post-translational modification of collagen in normal human articular cartilage. The age-related increase in nonenzymatic glycation affects biomechanical properties of cartilage. Biochem J 330: 345-351.

Bannister DW, Burns AB (1970) Adaptation of the Bergman and Loxley technique for hydroxyproline determination to the autoanalyser and its use in determining plasma hydroxyproline in the domestic fowl. Analyst 95: 596-600.

BenninghoffA (1925) Form und Bau der Gelenkknorpel in ihren Beziehungen zur Funktion. II. Der Aufbau des Gelenkknorpels in seinen Beziehungen zur Funktion. [Form and structure of articular cartilage in their relation to function. II. The structure of articular cartilage in its relation to function.] Z Zellforsch Mikrosk Anat 2: 783862 .

Bergman I, Loxley R (1963) Two improved and simplified methods for the spectrophotometric determination of hydroxyproline. Anal Chem 35: 19611965.

Brama PA, Tekoppele JM, Bank RA, Barneveld A, Van Weeren PR (2000) Functional adaptation of equine articular cartilage: The formation of regional biochemical characteristics up to age one year. Equine Vet J 32: 217 221.

Brommer H, Brama PA, Laasanen MS, Helminen HJ, Van Weeren PR, Jurvelin JS (2005) Functional adaptation of articular cartilage from birth to maturity under the influence of loading: a biomechanical analysis. Equine Vet J 37: 148-154. 
Buckwalter JA, Mankin HJ, Grodzinsky AJ (2005) Articular cartilage and osteoarthritis. Instr Course Lect 54: 465-480.

Canal Guterl C, Hung CT, Ateshian GA (2010) Electrostatic and non-electrostatic contributions of proteoglycans to the compressive equilibrium modulus of bovine articular cartilage. J Biomech 43: 1343-1350.

Chahine NO, Wang CCB, Hung CT, Ateshian GA (2004) Anisotropic strain-dependent material properties of bovine articular cartilage in the transitional range from tension to compression. J Biomech 37: 1251-1261.

Chen SS, Falcovitz YH, Schneiderman R, Maroudas A, Sah RL (2001) Depth-dependent compressive properties of normal aged human femoral head articular cartilage: Relationship to fixed charge density. Osteoarthritis Cartilage 9: 561-569.

Chung C, Burdick JA (2008) Engineering cartilage tissue. Adv Drug Delivery Rev 60: 243-262.

Etherington DJ, Sims TJ (1981) Detection and estimation of collagen. J Sci Food Agriculture 32: 539-546.

Farndale RW, Sayers CA, Barrett AJ (1982) A direct spectrophotometric microassay for sulfated glycosaminoglycans in cartilage cultures. Connect Tissue Res 9: 247-248.

Gannon AR, Nagel T, Kelly DJ (2012) The role of the superficial region in determining the dynamic properties of articular cartilage. Osteoarthritis Cartilage 20: 1417-1425.

Görke UJ, Günther H, Nagel T, Wimmer MA (2010) A large strain material model for soft tissues with functionally graded properties. J Biomech Eng 132: 074502.

Holzapfel GA, Gasser TC, Ogden RW (2000) A new constitutive framework for arterial wall mechanics and a comparative study of material models. J Elasticity 61: 1-48.

Hunziker EB (2002) Articular cartilage repair: Basic science and clinical progress. A review of the current status and prospects. Osteoarthritis Cartilage 10: 432-463.

Hunziker EB, Quinn TM, Häuselmann HJ (2002) Quantitative structural organization of normal adult human articular cartilage. Osteoarthritis Cartilage 10: 564-572.

Hunziker EB, Kapfinger E, Geiss J (2007) The structural architecture of adult mammalian articular cartilage evolves by a synchronized process of tissue resorption and neoformation during postnatal development. Osteoarthritis Cartilage 15: 403-413.

Hyttinen MM, Holopainen J, Van Weeren PR, Firth EC, Helminen HJ, Brama PA (2009) Changes in collagen fibril network organization and proteoglycan distribution in equine articular cartilage during maturation and growth. J Anat 215: 584-591.

Julkunen P, Harjula T, Iivarinen J, Marjanen J, Seppänen K, Närhi T, Arokoski J, Lammi MJ, Brama PA, Jurvelin JS, Helminen HJ (2009) Biomechanical, biochemical and structural correlations in immature and mature rabbit articular cartilage. Osteoarthritis Cartilage 17: $1628-1638$.

Julkunen P, Iivarinen J, Brama PA, Arokoski J, Jurvelin JS, Helminen HJ (2010) Maturation of collagen fibril network structure in tibial and femoral cartilage of rabbits. Osteoarthritis Cartilage 18: 406-415.
Khalsa PS, Eisenberg SR (1997) Compressive behavior of articular cartilage is not completely explained by proteoglycan osmotic pressure. J Biomech 30: 589-594.

Kim TK, Sharma B, Williams CG, Ruffner MA, Malik A, Mcfarland EG, Elisseeff JH (2003) Experimental model for cartilage tissue engineering to regenerate the zonal organization of articular cartilage. Osteoarthritis Cartilage 11: 653-664.

Király K, Hyttinen MM, Lapveteláinen T, Elo M, Kiviranta I, Dobai J, Módis L, Helminen HJ, Arokoski JPA (1997) Specimen preparation and quantification of collagen birefringence in unstained sections of articular cartilage using image analysis and polarizing light microscopy. Histochem J 29: 317-327.

Klein TJ, Schumacher BL, Schmidt TA, Li KW, Voegtline MS, Masuda K, Thonar EJMA, Sah RL (2003) Tissue engineering of stratified articular cartilage from chondrocyte subpopulations. Osteoarthritis Cartilage 11: 595-602.

Klein TJ, Chaudhry M, Bae WC, Sah RL (2007) Depthdependent biomechanical and biochemical properties of fetal, newborn, and tissue-engineered articular cartilage. J Biomech 40: 182-190.

Kock LM, Ito K, Van Donkelaar CC (2013) Sliding indentation enhances collagen content and depthdependent matrix distribution in tissue-engineered cartilage constructs. Tissue Eng Part A 19: 1949-1959.

Korhonen RK, Laasanen MS, Töyräs J, Lappalainen R, Helminen HJ, Jurvelin JS (2003) Fibril reinforced poroelastic model predicts specifically mechanical behavior of normal, proteoglycan depleted and collagen degraded articular cartilage. J Biomech 36: 1373-1379.

Maas SA, Ellis BJ, Ateshian GA, Weiss JA (2012) FEBio: Finite elements for biomechanics. J Biomech Eng 134: 011005.

Malda J, De Grauw JC, Benders KEM, Kik MJL, Van De Lest CHA, Creemers LB, Dhert WJA, Van Weeren PR (2013) Of mice, men and elephants: the relation between articular cartilage thickness and body mass. PLoS ONE 8: e57683.

Maroudas A (1979) Physio-chemical properties of articular cartilage. In: Freeman MAR (ed) Adult Articular Cartilage, 2nd ed. Pitman, Tunbridge Wells, pp 215-290.

Moutos FT, Freed LE, Guilak F (2007) A biomimetic three-dimensional woven composite scaffold for functional tissue engineering of cartilage. Nature Mater 6: 162-167.

Nagel T, Kelly DJ (2010) The influence of fiber orientation on the equilibrium properties of neutral and charged biphasic tissues. J Biomech Eng 132: 114506.

Nagel T, Kelly DJ (2013) The composition of engineered cartilage at the time of implantation determines the likelihood of regenerating tissue with a normal collagen architecture. Tissue Eng Part A 19: 824-833.

Ng KW, Wang CCB, Mauck RL, Kelly TaN, Chahine NO, Costa KD, Ateshian GA, Hung CT (2005) A layered agarose approach to fabricate depth-dependent inhomogeneity in chondrocyte-seeded constructs. J Orthop Res 23: 134-141.

Ng KW, Ateshian GA, Hung CT (2009) Zonal chondrocytes seeded in a layered agarose hydrogel create engineered cartilage with depth-dependent cellular and 
mechanical inhomogeneity. Tissue Eng Part A 15: $2315-$ 2324.

Nguyen LH, Kudva AK, Guckert NL, Linse KD, Roy K (2011) Unique biomaterial compositions direct bone marrow stem cells into specific chondrocytic phenotypes corresponding to the various zones of articular cartilage. Biomaterials 32: 1327-1338.

Nieminen MT, Rieppo J, Silvennoinen J, Töyräs J, Hakumäki JM, Hyttinen MM, Helminen HJ, Jurvelin JS (2002) Spatial assessment of articular cartilage proteoglycans with Gd-DTPA-enhanced T1 imaging. Magn Reson Med 48: 640-648.

Rieppo J, Hyttinen MM, Halmesmaki E, Ruotsalainen H, Vasara A, Kiviranta I, Jurvelin JS, Helminen HJ (2009) Changes in spatial collagen content and collagen network architecture in porcine articular cartilage during growth and maturation. Osteoarthritis Cartilage 17: 448-455.

Roth V, Mow VC (1980) The intrinsic tensile behavior of the matrix of bovine articular cartilage and its variation with age. J Bone Joint Surg Am 62: 1102-1117.

Schinagl RM, Ting MK, Price JH, Sah RL (1996) Video microscopy to quantitate the inhomogeneous equilibrium strain within articular cartilage during confined compression. Ann Biomed Eng 24: 500-512.

Schinagl RM, Gurskis D, Chen AC, Sah RL (1997) Depth-dependent confined compression modulus of fullthickness bovine articular cartilage. J Orthop Res 15: 499-506.

Schlichting N, Dehne T, Mans K, Endres M, Stuhlmüller B, Sittinger M, Kaps C, Ringe J (2014) Suitability of porcine chondrocyte micromass culture to model osteoarthritis in vitro. Mol Pharm 11: 2092-2105.

Schneider CA, Rasband WS, Eliceiri KW (2012) NIH Image to ImageJ: 25 years of image analysis. Nat Methods 9: 671-675.

Sharma B, Williams CG, Kim TK, Sun D, Malik A, Khan M, Leong K, Elisseeff JH (2007) Designing zonal organization into tissue-engineered cartilage. Tissue Eng 13: $405-414$.

Soltz MA, Ateshian GA (2000) Interstitial fluid pressurization during confined compression cyclical loading of articular cartilage. Ann Biomed Eng 28: 150159.

Soulhat J, Buschmann MD, Shirazi-Adl A (1999) A fibril-network-reinforced biphasic model of cartilage in unconfined compression. J Biomech Eng 121: 340-347.

Stockwell RA (1970) Changes in the acid glycosaminoglycan content of the matrix of ageing human articular cartilage. Ann Rheum Dis 29: 509-515.

Temple MM, Bae WC, Chen MQ, Lotz M, Amiel D, Coutts RD, Sah RL (2007) Age- and site-associated biomechanical weakening of human articular cartilage of the femoral condyle. Osteoarthritis Cartilage 15: $1042-$ 1052 .

Thorpe SD, Nagel T, Carroll SF, Kelly DJ (2013) Modulating gradients in regulatory signals within mesenchymal stem cell seeded hydrogels: a novel strategy to engineer zonal articular cartilage. PLoS ONE 8: e60764.

Torzilli PA, Grande DA, Arduino JM (1998) Diffusive properties of immature articular cartilage. J Biomed Mater Res 40: 132-138.
Vanden Berg-Foels WS, Scipioni L, Huynh C, Wen X (2012) Helium ion microscopy for high-resolution visualization of the articular cartilage collagen network. J Microsc 246: 168-176.

Wachtel E, Maroudas A, Schneiderman R (1995) Agerelated changes in collagen packing of human articular cartilage. Biochim Biophys Acta 1243: 239-243.

Wang CB, Mow VC (1998) Effects of aggregate modulus inhomogeneity on cartilage compressive stressrelaxation behavior. ASME-Publications-BED 39: 261262.

Wang CCB, Deng JM, Ateshian GA, Hung CT (2002) An automated approach for direct measurement of twodimensional strain distributions within articular cartilage under unconfined compression. J Biomech Eng 124: 557 567.

Wang CCB, Chahine NO, Hung CT, Ateshian GA (2003) Optical determination of anisotropic material properties of bovine articular cartilage in compression. $\mathrm{J}$ Biomech 36: 339-353.

Williamson AK, Chen AC, Sah RL (2001) Compressive properties and function-composition relationships of developing bovine articular cartilage. J Orthop Res 19: 1113-1121.

Williamson AK, Chen AC, Masuda K, Thonar EJMA, Sah RL (2003) Tensile mechanical properties of bovine articular cartilage: Variations with growth and relationships to collagen network components. J Orthop Res 21: 872880 .

Wilson W, Van Donkelaar CC, Van Rietbergen B, Huiskes R (2005) A fibril-reinforced poroviscoelastic swelling model for articular cartilage. J Biomech 38: 1195 1204.

Wilson W, Huyghe JM, Van Donkelaar CC (2007) Depth-dependent compressive equilibrium properties of articular cartilage explained by its composition. Biomech Model Mechanobiol 6: 43-53.

\section{Discussion with Reviewers}

Reviewer I: The remodelling activity within articular cartilage lead to profound changes in postnatal cartilage, developing from an isotropic environment to an ordered tissue. What do you believe are the predominant mechanisms by which the chondrocyte can orchestrate this incredible change in tissue ultrastructure?

Authors: Chondrocytes respond to mechanical load as a means of regulating the growth and differentiation of cartilage tissue throughout development and maturation (Sanchez-Adams et a1., 2014). A number of key transduction mechanisms have been identified that facilitate the mechanically-driven enhancement of cartilage extracellular matrix biosynthesis and functional properties, including mechano-sensitive ion channels and signalling through integrins and primary cilia (SanchezAdams et al., 2014; Phan et al., 2009). Furthermore, the pericellular matrix has emerged as a potential transducer of mechanical signals in cartilage, showing an ability to either amplify or attenuate local mechanical strains, as well as to convert tissue deformation to physicochemical 
(Haider et al., 2006) or biochemical changes (Vincent et al., 2004) in the chondrocyte microenvironment (Sanchez-Adams et al., 2014). Hence, the chondrocyte is uniquely equipped to sense and respond to changes in its mechanical environment during postnatal development. The culmination of the modelling/remodelling activity (mediated by chondrocytes through the mechanisms described above) to control cellular strains (or other mechanical inputs) throughout the tissue depth is one possible explanation for the alterations in the cartilage ultrastructure observed during postnatal development. For example, this might be to ensure a uniform mechanical environment for the chondrocytes themselves, or perhaps to protect these cells from injurious strain/loading.

Reviewer II: The authors need to justify the added value of the computational model.

Authors: The computational model offers us additional insight that we cannot gain directly through the experiments. As such, it represents a strong feature of the current study and allows us to get a feel for what is going on. While the influence of GAGs on the bulk stiffness of cartilage has been extensively investigated, the collagen network's contribution is more involved and not intuitively obvious. We do know by now that collagen fibre buckling is one of the main causes for the apparent softening observed in certain strain regions. However, the differential effects of collagen network stiffness and alignment on the bulk mechanical properties of a cartilage sample in unconfined compression are not clear and cannot be strictly separated experimentally. Therefore, the purpose of the set of simulations used in this study was to create an environment in which changing bulk mechanical properties could be attributed to isolated and controlled variations of collagen network stiffness and orientation without the additional complication of variations in other tissue properties.

Reviewer III: How would aged/degenerate cartilage fit into this model? What would the authors expect to uncover for the relationship in biochemistry and biomechanics to the neonatal or skeletally mature cartilage?

Authors: Osteoarthritis (OA) is generally diagnosed radiographically by bony changes, including osteophyte formation, cysts, subchondral sclerosis, cortical plate thickening and joint space narrowing (Griffin and Guilak, 2005). There is disagreement across the literature about whether these bone changes are concurrent with, primary to, or secondary to cartilage deterioration. Clinical observation suggests that bone density and cartilage fibrillation are inversely related (Burr and Schaffler, 1997). Cortical plate thickening in knee OA is caused by tidemark advancement (reduplication) following vascular invasion of the calcified cartilage at the bone-cartilage interface, as well as deposition of woven bone at the bone-marrow interface (Messent et al., 2005). A small amount of reduplication can exert a profound effect on focal increases in the overlaying articular cartilage and could contribute to cartilage loss in OA (Johnson et al., 1991). This gives rise to the hypothesis that cartilage fibrillation in OA is not solely dependent on stiffening of the subchondral plate but rather by a remodelling process in both subchondral bone and calcified cartilage that cause alterations of articular cartilage both biologically and mechanically (Burr and Schaffler, 1997). These biological alterations of articular cartilage include chondrocyte clustering, as a result of increased cell proliferation, and a general upregulation of synthetic activity associated with increased production of specific extracellular matrix proteins (Goldring and Goldring, 2010). As the pathological progression of OA continues, there is evidence of increased catabolic activity related to enhanced production of degradative proteinase genes associated with gradual loss of proteoglycans followed by type II collagen degradation (Goldring and Goldring, 2010). These alterations to the articular cartilage and underlying subchondral bone would have a profound effect on the mechanical response of the tissue to load; including decreases in the modulus or stiffness of OA cartilage in tension, compression and shear loading, and increases in the propensity to swell as compared to healthy cartilage (Gannon et al., 2012; Setton et al., 1999). These are different tissue and joint changes from that observed here during postnatal development. However, we believe the general findings reported in this study will provide greater insight into our understanding of cartilage mechanics in disease. Furthermore, computational models such as that utilised in this study can help provide greater insight into how structural and compositional changes in disease impact upon the functionality of the tissue.

Reviewer III: Would mechanical injury or overload to the same age groups tested drastically change the observed results? Imagine the availability of a bioreactor with cyclic mechanical stimulation. If this injury was applied to living tissue explants, would the tissue evolve and behave the same way?

Authors: We do not believe we could recapitulate the complex development of articular cartilage in a bioreactor. It is likely that the response of articular cartilage to mechanical injury will depend strongly on skeletal maturity, with the capacity of the tissue to resist overload increasing with age. In saying that, as articular cartilage acts as a growth plate during joint development, it is likely that immature tissue has a greater capacity for self-repair than skeletally mature tissue.

\section{Additional References}

Burr DB, Schaffler MB (1997) The involvement of subchondral mineralized tissues in osteoarthrosis: quantitative microscopic evidence. Microsc Res Tech 37: 343-357.

Goldring MB, Goldring SR (2010) Articular cartilage and subchondral bone in the pathogenesis of osteoarthritis. Ann N Y Acad Sci 1192: 230-237.

Griffin TM, Guilak F (2005) The role of mechanical loading in the onset and progression of osteoarthritis. Exerc Sport Sci Rev 33: 195-200.

Haider MA, Schugart RC, Setton LA, Guilak F (2006) A mechano-chemical model for the passive swelling response of an isolated chondron under osmotic loading. Biomechan Model Mechanobiol 5: 160-171. 
Johnson IA (1991) Stress transmission through multipe elastic layers. Thesis, Oxford University: Oxford, UK.

Messent EA, Ward RJ, Tonkin CJ, Buckland-Wright C (2005) Cancellous bone differences between knees with early, definite and advanced joint space loss; a comparative quantitative macroradiographic study. Osteoarthritis Cartilage 13: 39-47.

Phan MN, Leddy HA, Votta BJ, Kumar S, Levy DS, Lipshutz DB, Lee SH, Liedtke W, Guilak F (2009) Functional characterization of TRPV4 as an osmotically sensitive ion channel in porcine articular chondrocytes. Arthritis Rheum 60: 3028-3037.
Sanchez-Adams J, Leddy HA, McNulty AL, O'Conor CJ, Guilak F (2014) The mechanobiology of articular cartilage: bearing the burden of osteoarthritis. Curr Rheumatol Rep 16: 451.

Setton LA, Elliott DM, Mow VC (1999) Altered mechanics of cartilage with osteoarthritis: human osteoarthritis and an experimental model of joint degeneration. Osteoarthritis Cartilage 7: 2-14.

Vincent TL, Hermansson MA, Hansen UN, Amis AA, Saklatvala J (2004) Basic fibroblast growth factor mediates transduction of mechanical signals when articular cartilage is loaded. Arthritis Rheum 50: 526-533. 